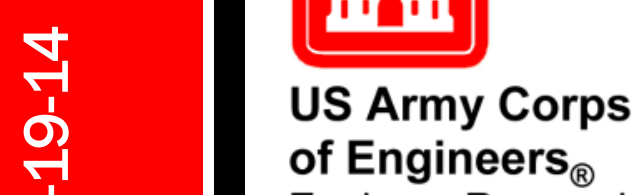

\title{
WERDC
}

Engineer Research and

Development Center

ERDC 6.2 Boreal Aspects of Ensured Maneuver (BAEM)

\section{SnowMicroPenetrometer Applications for Winter Vehicle Mobility}

Tate G. Meehan, Hans-Peter Marshall, Elias J. Deeb,

August 2019

and Sally A. Shoop

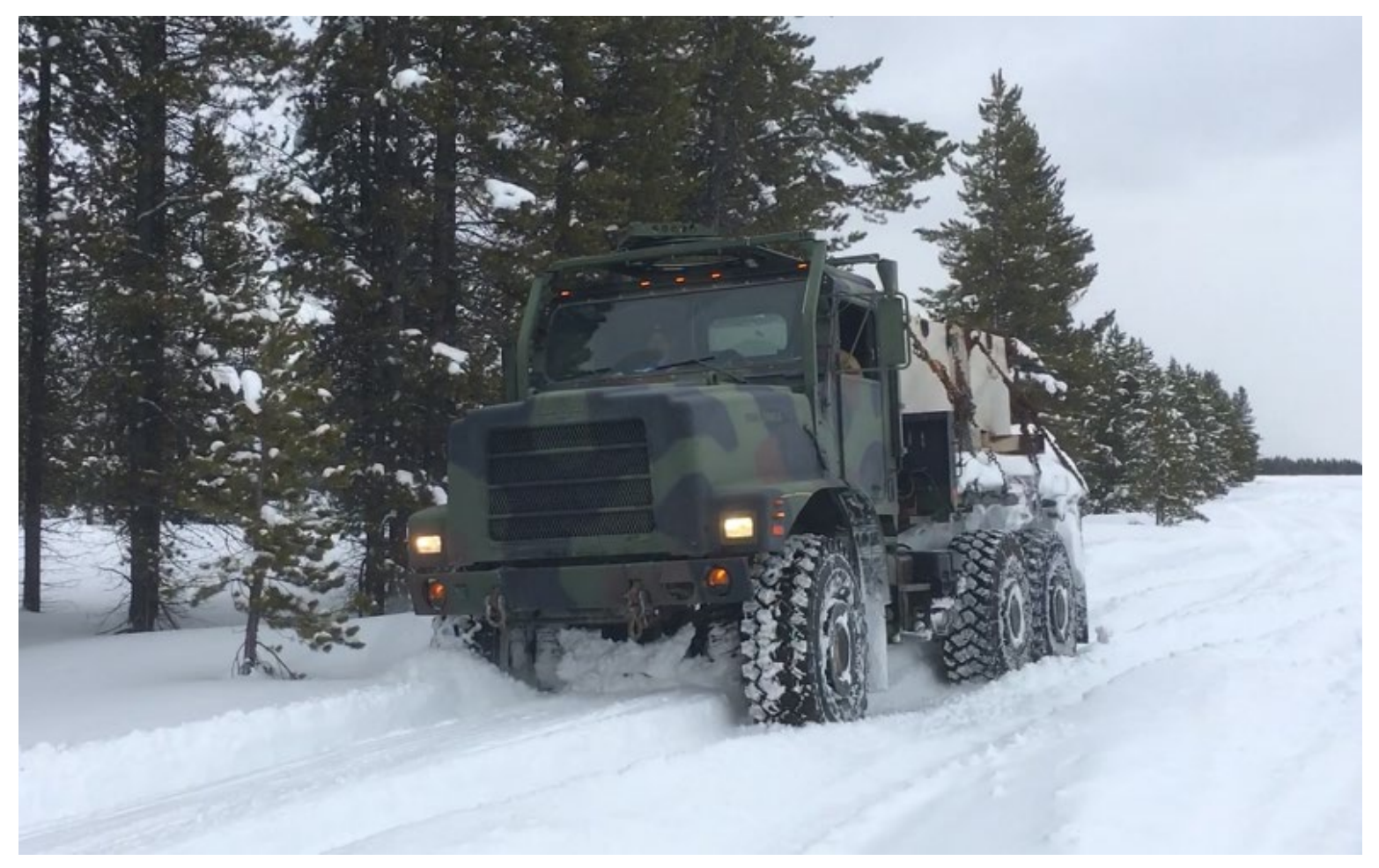


The U.S. Army Engineer Research and Development Center (ERDC) solves the nation's toughest engineering and environmental challenges. ERDC develops innovative solutions in civil and military engineering, geospatial sciences, water resources, and environmental sciences for the Army, the Department of Defense, civilian agencies, and our nation's public good. Find out more at www.erdc.usace.army.mil.

To search for other technical reports published by ERDC, visit the ERDC online library at http://acwc.sdp.sirsi.net/client/default. 


\section{SnowMicroPenetrometer Applications for Winter Vehicle Mobility}

Tate G. Meehan, Hans-Peter Marshall, Elias J. Deeb, and Sally A. Shoop

U.S. Army Engineer Research and Development Center (ERDC)

Cold Regions Research and Engineering Laboratory (CRREL)

72 Lyme Road

Hanover, NH 03755-1290

Final Report

Approved for public release; distribution is unlimited.

Prepared for Assistant Secretary of the Army for Acquisition, Logistics, and Technology 103 Army Pentagon

Washington, DC 20314-1000

Under Project 465395, ERDC 6.2 "Boreal Aspects of Ensured Maneuver (BAEM)," and Project 471941, "Remote Assessment of Snow Mechanical Properties" and "Mobility in Peat and Northern Soils" 


\section{Abstract}

The U.S. Army Cold Regions Research and Engineering Laboratory provides technical support to military forces, one area being vehicle mobility modeling over snow. Many factors control vehicle performance, including the vehicle specifications and the land surface conditions. However, estimating snow macromechanical properties-such as elastic modulus, stiffness, and strength-is critical for understanding how effectively a vehicle will travel over snow-covered terrain. Vehicle instrumentation data and observations of the snow pack are necessary to improve the estimates of winter vehicle performance. Currently, snow depth and bulk snow density alone drive the available mobility performance index.

This research deployed a SnowMicroPenetrometer (SMP) to measure hard, vehicle-compacted snow and groomed snow roads. Microstructural and micromechanical properties derived from the SMP data analysis were correlated to the Rammsonde penetrometer hardness, an established snow instrument, and to the shear-strength test vane and Light Weight Deflectometer, which are common in soil and aggregate layer assurance methods in road construction. Correlating these tools requires a new theory for inverting SMP signals for micromechanical properties that relaxes the assumption of low-density snow. Additionally, a scaling law appropriate to this type of hard snow is required to relate the SMP observations of the microscale and the macroscale properties.

DISCLAIMER: The contents of this report are not to be used for advertising, publication, or promotional purposes. Citation of trade names does not constitute an official endorsement or approval of the use of such commercial products. All product names and trademarks cited are the property of their respective owners. The findings of this report are not to be construed as an official Department of the Army position unless so designated by other authorized documents. 


\section{Contents}

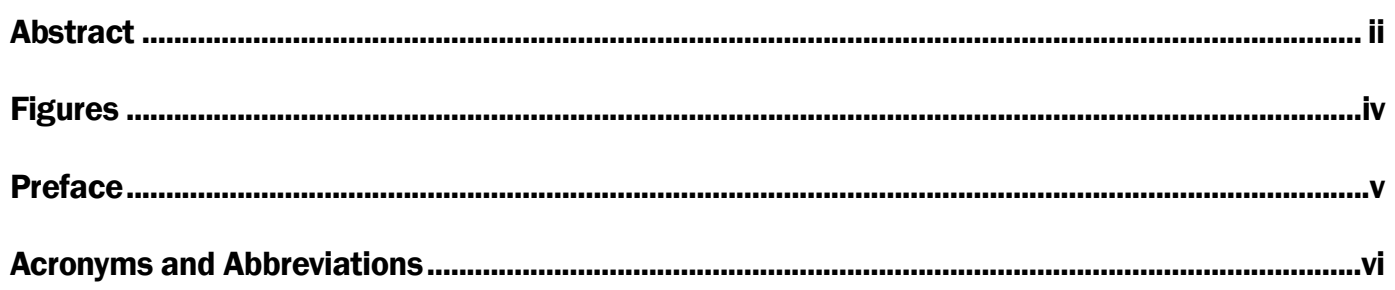

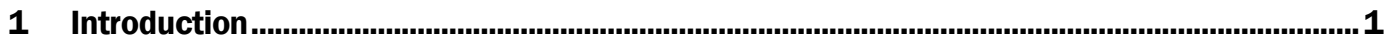

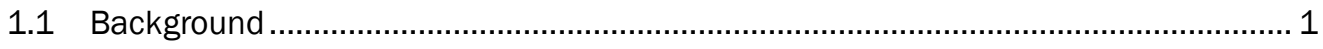

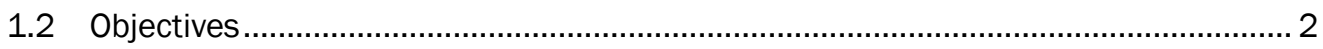

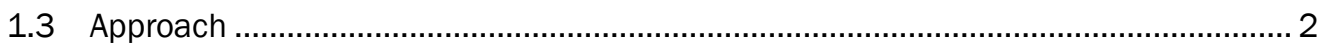

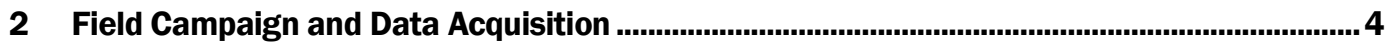

2.1 Study-site background ........................................................................................ 4

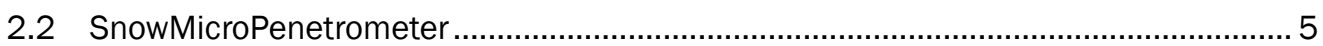

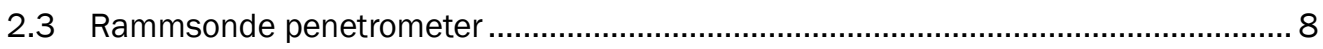

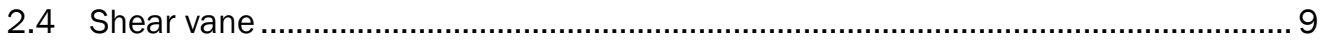

2.5 Light Weight Deflectometer.......................................................................... 10

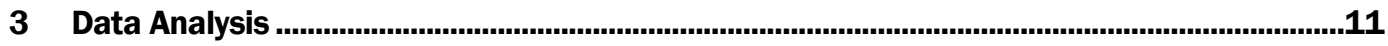

3.1 SMP automated signal processing .............................................................. 11

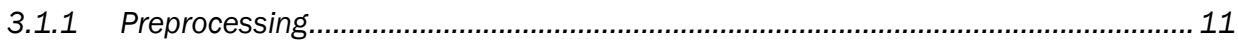

3.1.2 Correction for instrument drift............................................................................ 12

3.1.3 Correction for snow surface and depth ................................................................ 13

3.2 SMP data inversion for snow microstructural and micromechanical properties .................................................................................................. 13

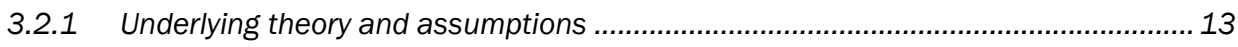

3.2.2 Monte Carlo data inversion scheme .................................................................... 14

3.2.3 Microstructural parameters................................................................................. 15

3.2.4 Derived snow microstructural parameters ............................................................ 15

3.2.5 Derived micromechanical properties..................................................................... 16

3.2.6 Inversion parameters and force resolution .......................................................... 17

3.3 Instrument observation correlation analysis.......................................................... 19

3.3.1 Theory of linear correlation.................................................................................... 19

3.3.2 Application of linear correlation .......................................................................... 20

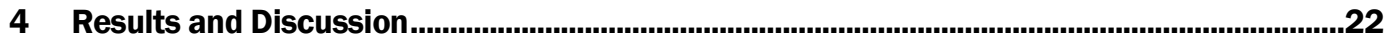

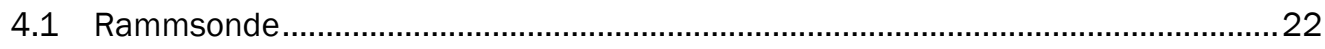

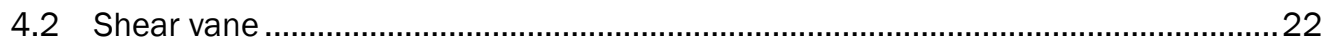

4.3 Light Weight Deflectometer........................................................................... 27

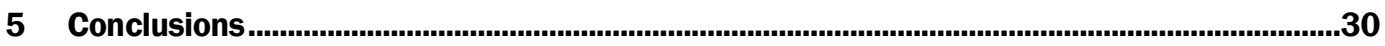

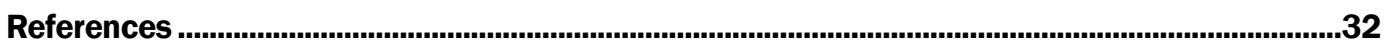




\section{Figures}

1 Satellite imagery of the NATC facility at the West Yellowstone airport during snow-off conditions. Waypoints plotted indicate the locations studied during the field campaign

2 The SMP mounted on a sled at the West Yellowstone airfield during the NATC campaign. The SMP was developed and designed by Dr. Martin Schneebeli (SLF) and Dr. Jerome Johnson (CRREL) in the mid-1990s. The pictured sled was designed and built by Dr. Matthew Sturm (CRREL)

3 Example SMP hardness profiles acquired in the three important snow conditions: virgin snow, snow trafficked by multiple vehicles, and a tire rut. SMP force profiles are shown after signal processing. The signal-processing algorithm automatically identifies the snow surface, indicated by the red $X$. NIR photographs corresponding to the snow pits where the SMP profiles are located show the major stratigraphic features. The SMP is capable of identifying snow layers not obvious to the eye or to manual measurements.

$4 \quad$ CRREL's Dr. Sally Shoop using the ram to measure the hardness of a vehicle belly drag after a coast-down test at NATC

5 A C4-type SMP trace through virgin snow before and after the snowsurface detection and drift correction. The depth axes of each plot must be reconfigured to place the snow surface at $0 \mathrm{~mm}$ depth

6 The three microstructural parameters $L, f$, and $\delta$ are estimated via the Monte Carlo data inversion. The objective of the data inversion is to use the summed signal $(F)$ as measured by the SMP to invert for the basic microstructural parameters $(L, f, \delta)$.

The boxplots of the instrument noise floor for increasing window lengths.

8 The drift-corrected SMP trace, as in Figs. 3 and 5, tested at force thresholds that distinguished null-rupture events. Data segments that did not experience any detectable ruptures of snow elements are shown in red. We recommend the $0.0195 \mathrm{~N}$ threshold because the air signal is correctly identified and C3 error type is minimized

9 The boxplot summary of SMP and ram data that yield significant correlation $(p \leq 0.05)$. The red crosses are outliers.

10 Statistically significant correlations between SMP microphysical parameters and the ram. The marker style identifies the site location, and the color represents the snow type.

11 Results of the correlation between the ram hardness index and the SMP microphysical parameters

12 Statistically significant correlations between SMP microphysical parameters and the shear-vane measurements $(p \leq 0.1)$. The boxplot summarizes the shear-vane measurements from 11 test locations

13 Results of the correlation between shear-vane stress and the SMP microphysical parameters

14 Results for the effective linear elastic property of groomed snow roads at NATC. Locations with negative slope or $p$-value $>0.05$ were excluded from the correlation analysis.

15 Results of the correlation analysis between $E^{\star}$ and the SMP microphysical parameters. No significant correlation was found 


\section{Preface}

This study was conducted for the Assistant Secretary of the Army for Acquisition, Logistics, and Technology under project number 465395, "Boreal Aspects of Ensured Maneuver (BAEM)," which is part of the U.S. Army Engineer Research and Development Center (ERDC) 6.2 Remote Assessment of Infrastructure for Ensured Maneuver (RAFTER) Program managed by Ms. Danielle Whitlow ERDC Geotechnical and Structures Laboratory (GSL). This work is continuing under project number 471941, "Remote Assessment of Snow Mechanical Properties" and "Mobility in Peat and Northern Soils," under the Entry and Sustainment in Complex Contested Environments Program managed by Dr. John Rushing, GSL.

The work was performed by the Lidar and Wetlands Group and the Terrain and Ice Engineering Group of the Remote Sensing / Geographic Information System Center of Expertise (CEERD-RS) and the Force Projection and Sustainment Branch (CEERD-RRH) of the Research and Engineering Division (CEERD-RR), U.S. Army Engineer Research and Development Center, Cold Regions Research and Engineering Laboratory (ERDC-CRREL). At the time of publication, Dr. Elias Deeb was lead for the Lidar and Wetlands Group; Mr. Stephen Newman was lead for the Terrain and Ice Engineering Group; Mr. David Finnegan was Chief, CEERD-RS; Mr. Justin Putnam was Acting Chief, CEERD-RRH; and Mr. Jared Oren was Acting Chief, CEERD-RR. The Deputy Director of ERDC-CRREL was Mr. David B. Ringelberg, and the Director was Dr. Joseph L. Corriveau.

COL Ivan P. Beckman was Commander of ERDC, and Dr. David W. Pittman was the Director. 


\section{Acronyms and Abbreviations}

\begin{tabular}{|c|c|}
\hline BAEM & Boreal Aspect of Ensured Maneuver \\
\hline $\mathrm{C}$ & Center \\
\hline $\mathrm{CD}$ & Coast Down \\
\hline CRREL & Cold Regions Research and Engineering Laboratory \\
\hline ERDC & U.S. Army Engineer Research and Development Center \\
\hline GPS & Global Positioning System \\
\hline GSL & Geotechnical and Structures Laboratory \\
\hline LVSR & Logistics Vehicle System Replacement \\
\hline LWD & Light Weight Deflectometer \\
\hline MOBLP & Mobility Loop \\
\hline MTVR & Medium Tactical Vehicle Replacement \\
\hline $\mathrm{N}$ & North \\
\hline NATC & Nevada Automotive Test Center \\
\hline NIR & Near-Infrared \\
\hline ram & Rammsonde Penetrometer \\
\hline RAFTER & Remote Assessment of Infrastructure for Ensured Maneuver \\
\hline RWY & Runway \\
\hline $\mathrm{S}$ & South \\
\hline SD & Secure Digital \\
\hline SLF & Swiss Federal Institute for Snow and Avalanche Research \\
\hline SMP & SnowMicroPenetrometer \\
\hline TXY & Taxiway \\
\hline VS & Virgin Snow \\
\hline
\end{tabular}




\section{Introduction}

\subsection{Background}

The U.S. Engineer Research and Development Center (ERDC) Military Engineering Program on Remote Assessment of Infrastructure for Ensured Maneuver (RAFTER) Boreal Aspects of Ensured Maneuver (BAEM) identifies the need for modeling over-snow vehicle performance, as many factors related to vehicle setup and land surface condition contribute to vehicle efficiency. Accurately estimating snow macromechanical characteristics-such as elastic modulus, stiffness, and strength-is critical for understanding how effectively a vehicle will travel over snow-covered terrain. Vehicle instrumentation data (inertial measurement units and vehicle telemetry) and observations of the snowpack (both satellite and groundbased) are necessary to improve the modeled estimates of winter vehicle performance. Currently, performance index is driven by snow depth and bulk snow density alone.

The snow characterization research effort deploys a capability jointly developed by the ERDC Cold Regions Research and Engineering Laboratory (CRREL) and the Swiss Federal Institute for Snow and Avalanche Research (SLF) two decades ago-the SnowMicroPenetrometer (SMP) (Schneebeli and Johnson 1998). Our study used an SMP with a force sensor range of $0-500 \mathrm{~N}$ to measure hard, vehicle-compacted snow and processed or groomed snow roads. Median values of the high-resolution snow structural profiles from the SMP are linearly related to Rammsonde (ram), shear strength test vane, and Light Weight Deflectometer (LWD) by correlating values over the depth range of each independent in situ measurement. Statistically significant correlation shows the value of the SMP as a tool for future mobility studies in different snow types. By also understanding results that lack significant correlations, we gain insight for improving the SMP hardware, the penetration theory used, and the micro-tomacro scaling laws.

Winter vehicle mobility studies by CRREL have evaluated vehicle setup and snow condition (Shoop et al. 2014); however, the SMP has not previously been applied to a mobility study. This work is the first winter vehicle mobility study to examine the usefulness of the SMP for research on military vehicle efficiency. 


\subsection{Objectives}

The overarching objective of our research is to improve vehicle mobility modeling by incorporating additional snow physics. Characterizing the snow mechanical properties and their impact on vehicle mobility is challenging and requires varied field instruments and specialists with a wide range of expertise. This technical report overviews four instruments used to characterize snow for the BAEM project-the SMP, ram, shear vane, and LWD (sections 2.2-2.5)-and assesses required load-cell ranges of the SMP for its application to hard, vehicle-compacted snow. Within this report, we correlate the microphysical parameters estimated from SMP measurements to those from a suite of instruments designed or tested to measure snow mechanical properties. The work derived from this study aims to bridge micro-to-macro snow physics with the ultimate intent to infer snow structure from satellite imagery for use as initial and boundary conditions for vehicle mobility models.

\subsection{Approach}

The field site chosen for this study was the Nevada Automotive Test Center (NATC) in West Yellowstone, Montana. NATC leases the West Yellowstone Airport property from the Montana Department of Transportation Aeronautics Division for winter testing. During the winter, the airport is closed to air traffic, with the exception of emergency rescue helicopters. NATC maintains the site and the various test vehicles during the winter months. Our study, the NATC campaign, accomplishes the objectives through the following tasks:

- Perform vehicle tests in various snow-surface conditions at the NATC test site, West Yellowstone, Montana.

- Sample the snow within hours after vehicle tests with the suite of instruments. This includes manual measurements of snow depth, density, hardness, shear strength, deflection, dielectric permittivity, and near-infrared (NIR) photography.

- Develop automated signal processing for SMP analysis and solve for the snow microstructural properties, applying the method of Marshall and Johnson (2009).

- Apply statistical regression and analysis to draw correlations between the measurements of the ram, shear vane, LWD, and the microphysical parameters derived from the SMP. 
Our approach is limited by the abilities of the various instruments to measure particular snow types. The SMP had difficulty penetrating groomed snow roads, the ram and shear vane struggled measuring soft or virgin snow, and the LWD required groomed snow. 


\section{Field Campaign and Data Acquisition}

\subsection{Study-site background}

During late January 2018, NATC operated Marine Corps vehicles in several snow conditions (processed snow road, ice lane, trafficked snow, and virgin snow) using various performance setups (tire pressure configurations, differential configurations, towed/pulling/load carrying) to conduct mobility performance tests (traction, drag-bar, and coast down). During a coast-down test, the test vehicle is accelerated to a constant velocity on tarmac or groomed road before entering a virgin snowpack roughly $50 \mathrm{~cm}$ deep-through which the vehicle rolls to a stop. Beside coast-down tests, the other tests were simple vehicle passes through virgin or rutted snow. The CRREL and Boise State University snow characterization team measured the snowpack using a suite of instruments with the objective of recording the snow conditions before and after alteration by the military vehicles. In all test scenarios, measurements were taken in the resulting tracks and area between the tracks, where the undercarriage of the vehicle resulted in a belly drag that compacted the snow to a lesser degree.

This technical report discusses the results from data acquired using the SMP, ram, shear vane, and LWD (sections 2.2-2.5). Figure 1 is an aerial map of the NATC study site during the summer when the ground is not snow covered. It identifies the acquisition locations for each day of the NATC campaign. Throughout the data analysis, this report uses the following nomenclature: date (XX), cardinal location $(\mathrm{N}$ [north], $\mathrm{S}$ [south], and $\mathrm{C}$ [center]), snow type/location (RWY [runway], TXY [taxiway], MOBLP [mobility loop], and VS [virgin snow]), and vehicle name (e.g., MTVR [Medium Tactical Vehicle Replacement] and LVSR [Logistics Vehicle System Replacement]), and test type ( $\mathrm{CD}$ [coast down]) when applicable or unique. 
Figure 1. Satellite imagery of the NATC facility at the West Yellowstone airport during snow-off conditions. Waypoints plotted indicate the locations studied during the field campaign.

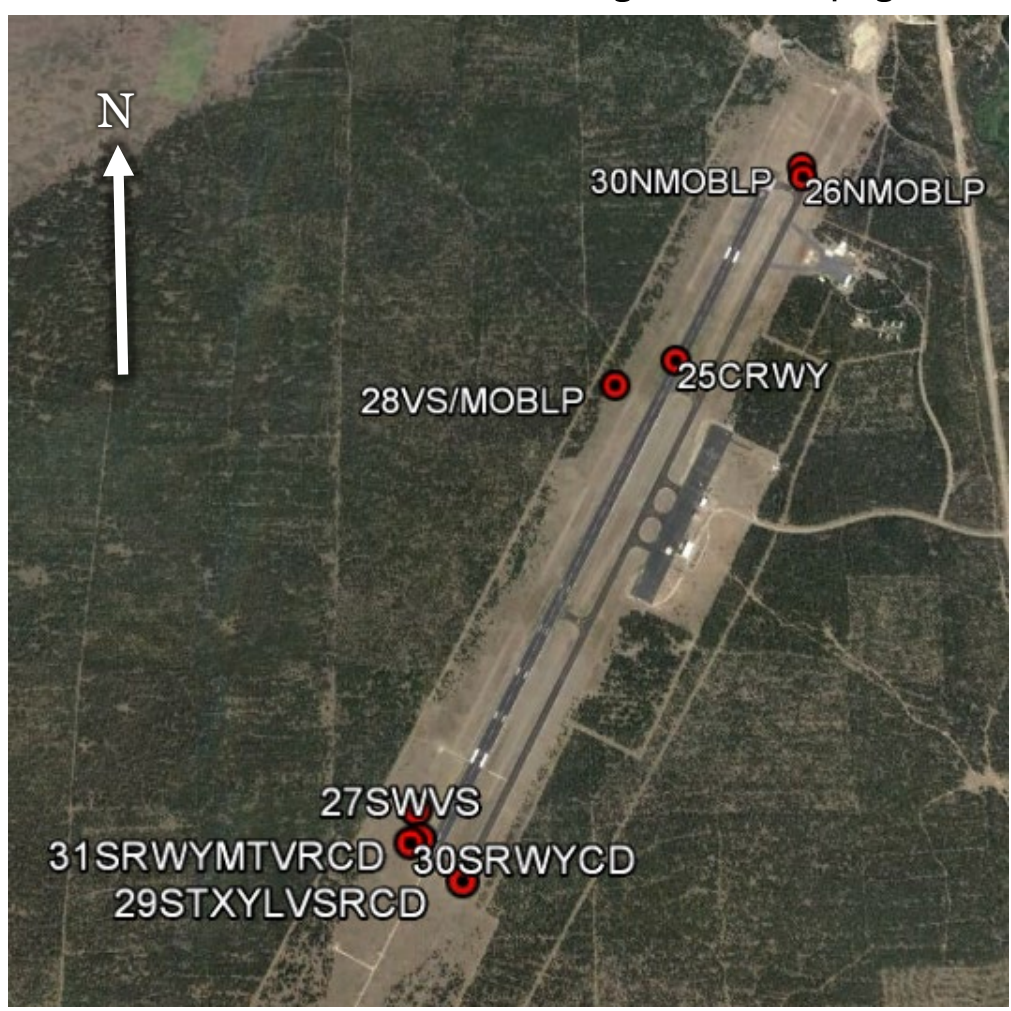

\subsection{SnowMicroPenetrometer}

The SMP (Figure 2) is a mechanically driven sonde penetrometer capable of measuring the hardness of the snowpack through high-resolution sampling of penetration force $(F)$ versus depth $(z)$, as the snow deforms in multiple modes (tension, compression, and shear). This instrument samples the penetration force 250 times per millimeter and drives through the snowpack at a rate of $20 \mathrm{~mm} / \mathrm{sec}$. This corresponds to a strain rate above $10^{-3}$, such that the snow behaves in a nearly linear elastic manner with brittle failure (Shapiro et al. 1997). Thus, in theory, the SMP is capable of measuring the individual ruptures of snow-grain bonds that are in contact with the penetrometer tip. The SMP was initially designed to operate in light alpine snowpacks and to be sensitive to structural weaknesses within the snowpack, at penetrations forces of approximately $0.01 \mathrm{~N}$, for understanding and assessing avalanche hazard (Schneebeli and Johnson 1998).

The standard SMP load cell is sensitive to a range of forces between $\mathrm{o}$ and $42 \mathrm{~N}$ (Pielmeier and Schneebeli 2003). For the NATC campaign, the SMP was equipped with a higher capacity load cell that enables the SMP to 
measure forces up to $500 \mathrm{~N}$. The hard-packed snow conditions created by and for the vehicle testing demand the increased dynamic range of the load cell, which has previously been used for hard wind-packed snow in the Arctic and Antarctic. The increased dynamic range comes at a cost in force resolution and noise floor, as the analog-to-digital converter used for both the low and high ranges is currently the same and the noise level is higher for the larger-range force sensor.

Figure 2. The SMP mounted on a sled at the West Yellowstone airfield during the NATC campaign. The SMP was developed and designed by Dr. Martin Schneebeli (SLF) and Dr. Jerome Johnson (CRREL) in the mid-1990s. The pictured sled was designed and built by Dr. Matthew Sturm (CRREL).

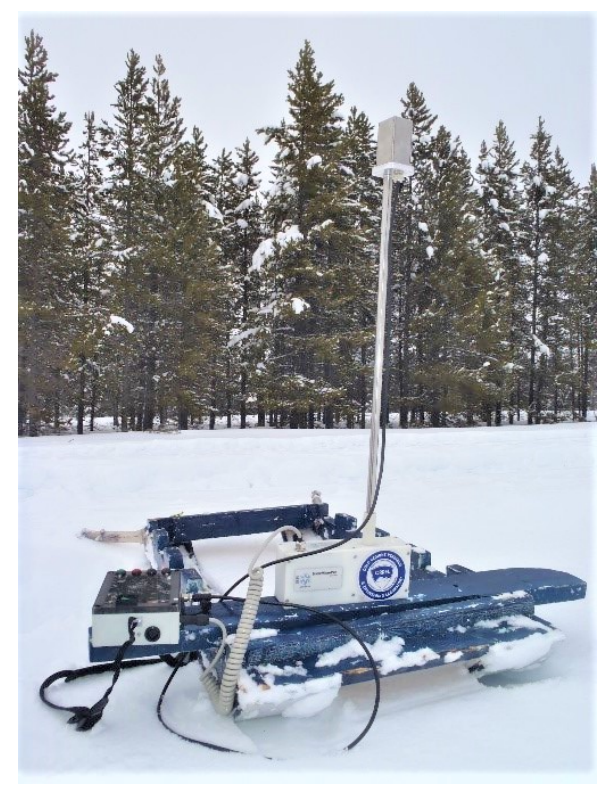

The SMP outputs a binary format data file (.pnt) that is unpacked using Python or MATLAB code. The Python code, SnowMicroPyn, was developed by SLF and is used primarily for extracting a GPS (Global Positioning System) location from the data header file. MATLAB scripts developed by Dr. H.P. Marshall and Tate Meehan are used for unpacking the data and performing the signal processing and inversion of the micromechanical and microstructural snow properties (Marshall and Johnson 2009).

The SMP can acquire high-resolution force resistance profiles rapidly and with little-to-no strenuous effort in the field. The SMP was mounted in a sled with two runners and an open floor. The SMP sled was indexed with 
five positions separated by $20 \mathrm{~cm}$ to allow for five acquisitions per sled location. After the five positions were acquired, the sled was advanced. This configuration allows for easy transport of the SMP across the snow without disturbing the snow beneath the penetrometer. The SMP is operated from a battery powered data logger console with an integrated GPS. The operator defines the depth of penetration for the profile. The SMP has a maximum penetration depth of $61 \mathrm{~cm}$. When the selected depth is reached or if the SMP is unable to penetrate (hard snow or the ground), the probe is automatically reversed. SMP profiles are individually stored in binary .pnt files on a removable SD (Secure Digital) card.

Data was acquired in a series of transects crossing perpendicular to the vehicle tracks. The typical transect would begin in the virgin snow; advance across the tire rut, the belly drag, and the second tire rut; and conclude in the virgin snow on the opposite side of the vehicle path. This resulted in five SMP test positions, each with five SMP measurements 20 $\mathrm{cm}$ apart in similar snow conditions, for each transect. Figure 3 presents the SMP penetration-force profiles after signal processing (section 3).

Figure 3. Example SMP hardness profiles acquired in the three important snow conditions: virgin snow, snow trafficked by multiple vehicles, and a tire rut. SMP force profiles are shown after signal processing. The signal-processing algorithm automatically identifies the snow surface, indicated by the red $X$. NIR photographs corresponding to the snow pits where the SMP profiles are located show the major stratigraphic features. The SMP is capable of identifying snow layers not obvious to the eye or to manual measurements.
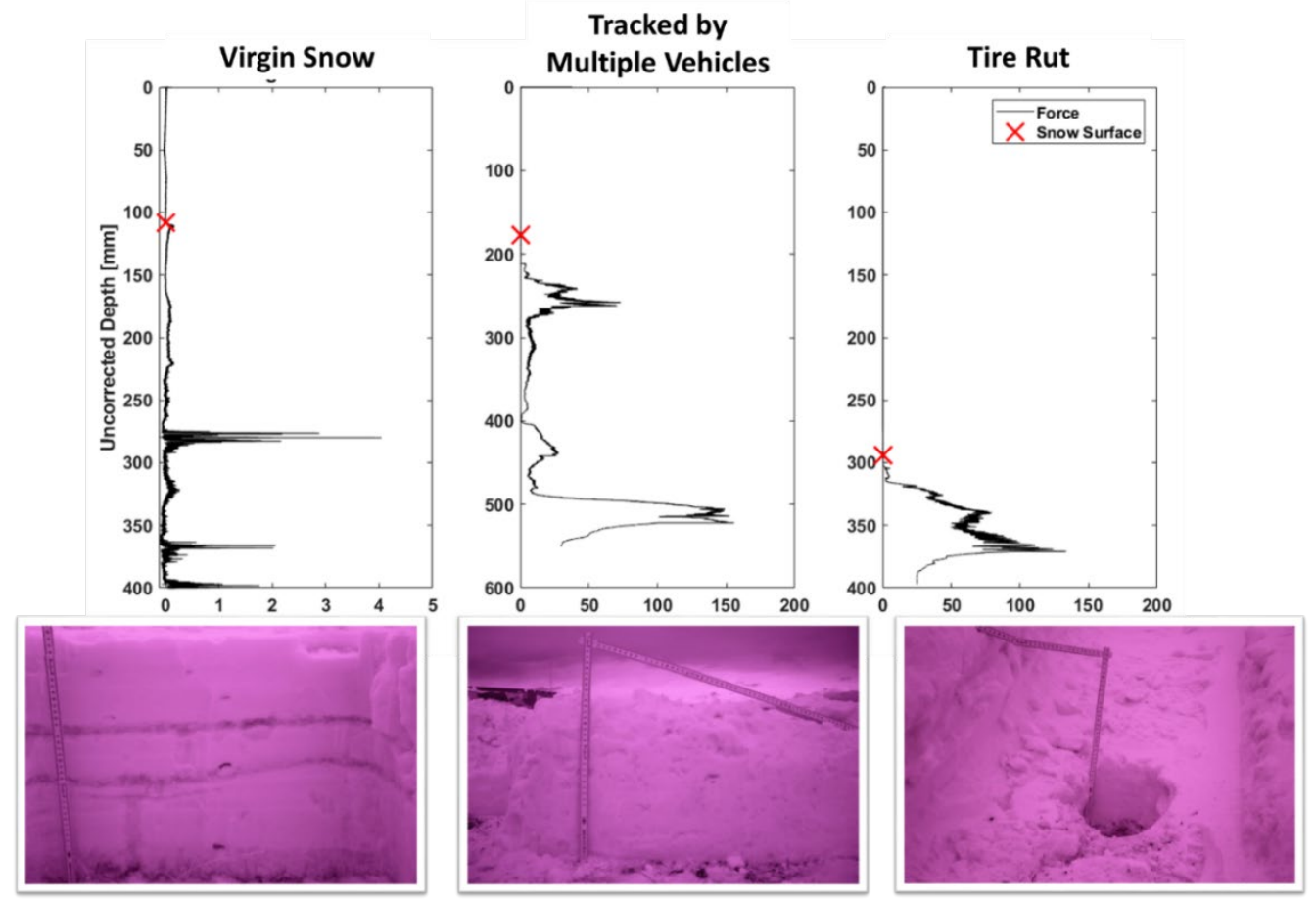
The snow surface is automatically picked within the signal-processing algorithm and is identified by a red $\mathrm{X}$. An air gap exists between the SMP and the snow surface. In virgin snow, this distance is approximately $10 \mathrm{~cm}$. When the SMP is suspended above a tire rut, this distance is greater, as shown in Figure 3 (right). NIR photographs corroborate the stratigraphic layers seen in the SMP profile through virgin snow. However, the stratigraphy is destroyed in trafficked snow and is not clearly visible in the NIR spectrum. The SMP is capable of resolving stratigraphic layers present in trafficked snow by measuring the snow penetration force with greater vertical resolution and sensitivity.

\subsection{Rammsonde penetrometer}

The ram penetrometer is one of the early hardness penetrometers (Bader 1954) and is the standard instrument for determining snow hardness in the field. The value of ram hardness indicates the resistance of individual snow layers to vertical penetration (Abele 1963). The ram (Figure 4) has the capability of retrieving a hardness measurement at the snow surface and within stratigraphic intervals of the snow, though measurements of ram hardness are typically reported as a bulk value over the measurement profile. Snow microstructural properties cannot be estimated from bulk measurements of ram hardness. Abele (1963) developed the correlation between unconfined compressive strength of processed snow and ram hardness and conveys the underlying theory and mechanics of the tool.

The snow characterization team manually tabulated in the field the data acquired by the ram. The important parameters to record are the hammer weight $(W)$, the drop height $(H)$, the weight of the penetrometer $(Q)$, the penetration depth per the number of hammer blows $\left(Z_{n}\right)$, and the number of hammer blows applied to achieve a penetration interval $(n)$. Abele (1963) provides an overview of the instrument design and equation (1) for calculating the ram hardness index $(R)$ :

$$
R=\frac{W H n}{z_{n}}+W+Q
$$

The ram team sampled each test location carefully as to not disturb the snow for its measurement or the measurements of the other instruments in the field. Ram hardness profiles were recorded in the virgin snow, belly drags, and tire ruts for comparison with the SMP profiles. 


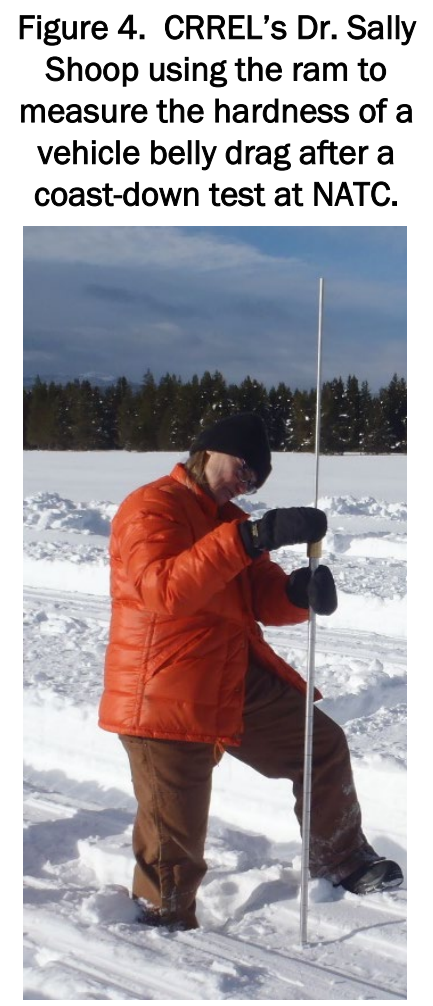

\subsection{Shear vane}

The team measured surface shear strength by using a Geonor H-6o handheld vane tester (henceforth shear vane). The shear vane has an orthogonal, cross-shaped blade. The standard vane blade and length come in three sizes, and the size is chosen based on the snow strength. Custom vane sizes are also sometimes used. The vane is inserted into the snow to a depth covering the entire vane, and then a steady turning force is applied until the snow shears. The maximum shear force is recorded as kilopascals. The shear-strength values for each site are the average of three measurements. ASTM D2573-18 (ASTM International 2018) covers the use of the shear vane in soils.

The shear-vane measurements were recorded at the snow surface of pits together with temperature, density, and snow height. Virgin and soft bellydrag snow provided insufficient strength for measurement with this tool with the exceptions of measurements made in vehicle belly drags on 30 January at the north mobility loop entrance and 31 January at the south runway, limiting the number of observations for this study. The operator manually recorded the maximum shear stress applied by this instrument. Shear-vane measurements were repeated several times at each snow pit to estimate the shear-strength distribution. 


\subsection{Light Weight Deflectometer}

The LWD measures the ground deflection when an impact load is applied to a plate that has a geophone at its center. The LWD is conventionally used for quality control and assurance of soil and aggregate layers in road construction. Using the LWD on snow surfaces is a new application for the device (Wieder et al. 2019). As the applied load increases, the deflection will increase for a linear, elastic material. Snow in many circumstances does not behave as a linear elastic material (Shapiro et al. 1997); however, at the high strain rates used in this study, a linear elastic approximation is reasonable. On 25 January 2018, the snow characterization team deployed the LWD on groomed snow surfaces over paved asphalt at high strain rate. Under these conditions, the snow was thought to be a rigid body and to behave elastically. Various geophone configurations were tested, yet only the central geophone recorded useable waveforms for analysis (Wieder et al. 2019).

SMP profiles were collected coincident with LWD tests on the processed snow road in ruts and unaltered surfaces. This shallow and hard snow proved difficult to penetrate with the SMP and harmed the instrument hardware. We examined a reduced sample of data in this study to compare the LWD and SMP and found no significant correlation between these instruments (section 4.3). 


\section{Data Analysis}

The snow characterization team acquired 383 SMP penetration-force profiles during the NATC campaign. The binary data files were read and processed repeatedly as a batch. Section 3.1 describes the Python and MATLAB codes that perform the signal processing. Section 3.2 outlines the data inversion and microphysical snow properties. Section 3.3 details the correlation analysis between the SMP-derived microphysical snow properties and the additional instruments.

\subsection{SMP automated signal processing}

\subsubsection{Preprocessing}

Signal preprocessing begins within the Python script provided by SLF for georeferencing the SMP trace with longitude and latitude coordinates with approximately $3 \mathrm{~m}$ accuracy. This information is exported as a .txt file that is read into the signal-processing code. The open-source Python code is used for this task only, and the following routines take place in MATLAB. The binary .pnt file is read into memory and written to a structure that contains the metadata and the SMP signal. GPS locations are then joined to the data structure.

Prior to spinning up the signal-processing routine, we reviewed each raw SMP trace for quality control. The classification strategy in Lutz (2009) and Pielmeier and Marshall (2009) was used to identify traces that have no error (C1), exhibit a linear trend and/or an offset in the trace (C2), exhibit dampened signal microvariance (segments of the trace that have lower variance than the normal air signal) $\left(\mathrm{C}_{3}\right)$, and traces that exhibits errors of types $\mathrm{C}_{2}$ and $\mathrm{C}_{3}\left(\mathrm{C}_{4}\right)$. Trends and offsets are corrected if the $\mathrm{C}_{2} \mathrm{er}-$ ror is observable in the air signal (section 3.1.3). Data that experiences $\mathrm{C}_{3}$ errors are prevalent in this study in low-strength virgin snow because of the reduction in resolution of the $500 \mathrm{~N}$ load cell. Snow element ruptures cannot be detected in data segments suffering from $\mathrm{C}_{3}$ errors (section 3.2.6). The quality control classifications are supplemental metadata that enable automation for drift correction and the snow-surface identification.

The processing routine first identifies the snow surface. A duplicate, temporary trace is smoothed with a $0.25 \mathrm{~mm}$ moving window average (62 samples). Smoothing aides in preventing false surface detection. The variance 
of the smoothed trace is then calculated within a $1 \mathrm{~mm}$ moving window. The program then extracts a segment of the trace while the penetrometer tip is driving through the air and calculates the mean variance of this segment. We establish a threshold variance of $49 \sigma^{2}$ relative to the mean variance of the extracted air signal. Once this threshold is exceeded, the program identifies the snow surface.

\subsubsection{Correction for instrument drift}

After repeated use, especially in wet conditions, moisture may migrate behind the penetrometer tip and cause a recognized phenomenon within the SMP signal (Lutz 2009); infrequently, the malfunction introduces a linear drift to the recorded SMP trace. Because the overall drift within the signal may be approximated by a linear function, a corrected force signal within the snow can be estimated by examining the signal as the tip is driven through the air. A least-squares fit is applied to the data above the snow surface to estimate the drift function. The drift function is then subtracted from the raw SMP trace, correcting the data. The raw trace shown in Figure 5 is type $\mathrm{C}_{4}$, as a linear trend and static offset is observable in the air signal and segments of the trace exhibit damped signal microvariance. Figure 5 demonstrates the result of the automated signal processing before and after snow-surface identification and drift correction.

Figure 5. A C4-type SMP trace through virgin snow before and after the snow-surface detection and drift correction. The depth axes of each plot must be reconfigured to place the snow surface at $0 \mathrm{~mm}$ depth.
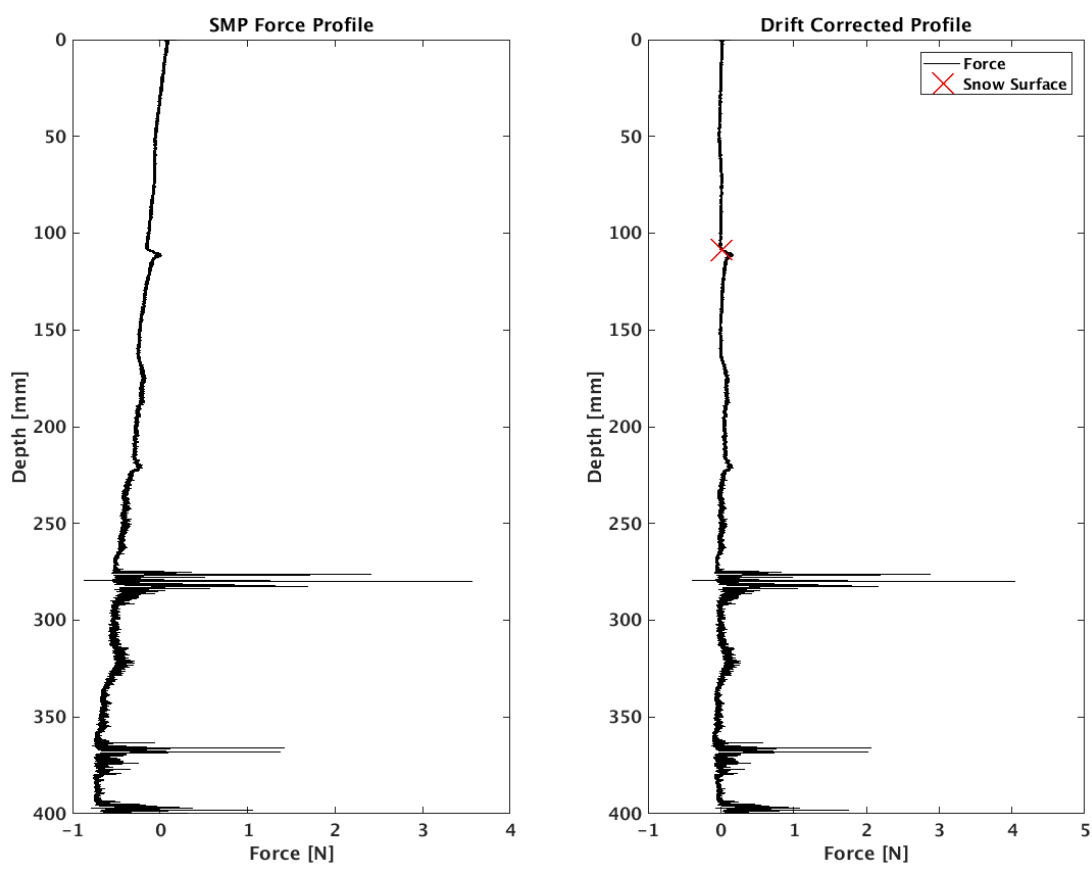


\subsubsection{Correction for snow surface and depth}

Because the SMP trace begins recording as the penetrometer moves initially through the air gap, the depth profile is shifted by the distance to the automatically detected snow surface, such that negative depths are in the air and positive depths are distances below the snow surface.

\subsection{SMP data inversion for snow microstructural and micromechanical properties}

\subsubsection{Underlying theory and assumptions}

The microstructure of snow controls its compressive, tensile, and shear strength (e.g., Shapiro et al. 1997; Marshall 2005) and is thereby important for understanding the mobility of vehicles through snow-covered terrain. A physics-based theory on snow penetration through lower-density snow was first developed by Johnson and Schneebeli (1999). This snow penetration theory models microstructural snow elements as a cellular solid ice matrix. Each element is assumed to have a constant dimension $(L)$ that is related to the number of measured ruptures per millimeter (Marshall and Johnson 2009). The snow element ruptures at a rupture force $(f)$ after some deflection length $(\delta)$ that is less than $L$. Snow deforming as a linear elastic material due to penetration may be defined by these basic microstructural parameters $(L, f, \delta)$ from the recorded failure of individual snow elements (Johnson and Schneebeli 1999; Marshall and Johnson 2009). Figure 6 depicts the individual snow element ruptures that are modeled by elastic events and are represented by the basic microstructural parameters $L, f$, and $\delta$.

This assumption is valid in low-density snow behaving as a foam where the compaction of snow elements is understood to be negligible. In the higher density regime $\left(400-600 \mathrm{~kg} / \mathrm{m}^{3}\right)$, snow behaves as a porous solid, and interelement compaction has an effect on the rupture of snow elements (Marshall and Johnson 2009), which is not accounted for in this theory. Anderson and Benson (1963) proposed that a rapid transition in the mechanical properties of dry snow exists in the density range 550$570 \mathrm{~kg} / \mathrm{m}^{3}$ as snow reaches the limit of densification caused by grain packing; further densification must occur by changes to the bonds interconnecting grains. We applied the penetration theory developed for low-density snow to the NATC study, though snow densities for vehicle-driven snow and groomed snow roads are reported in the porous solid regime 
(Shoop et al. 2016). Beyond the scope of this report, we recommend developing additional physical theory to account for intergranular effects on rupture force caused by the closeness of grain packing and the development of grain bonding in addition to accounting for compaction of grains and bonds.

Figure 6 . The three microstructural parameters $L, f$, and $\delta$ are estimated via the Monte Carlo data inversion. The objective of the data inversion is to use the summed signal $(F)$ as measured by the SMP to invert for the basic microstructural parameters $(L, f, \delta)$.

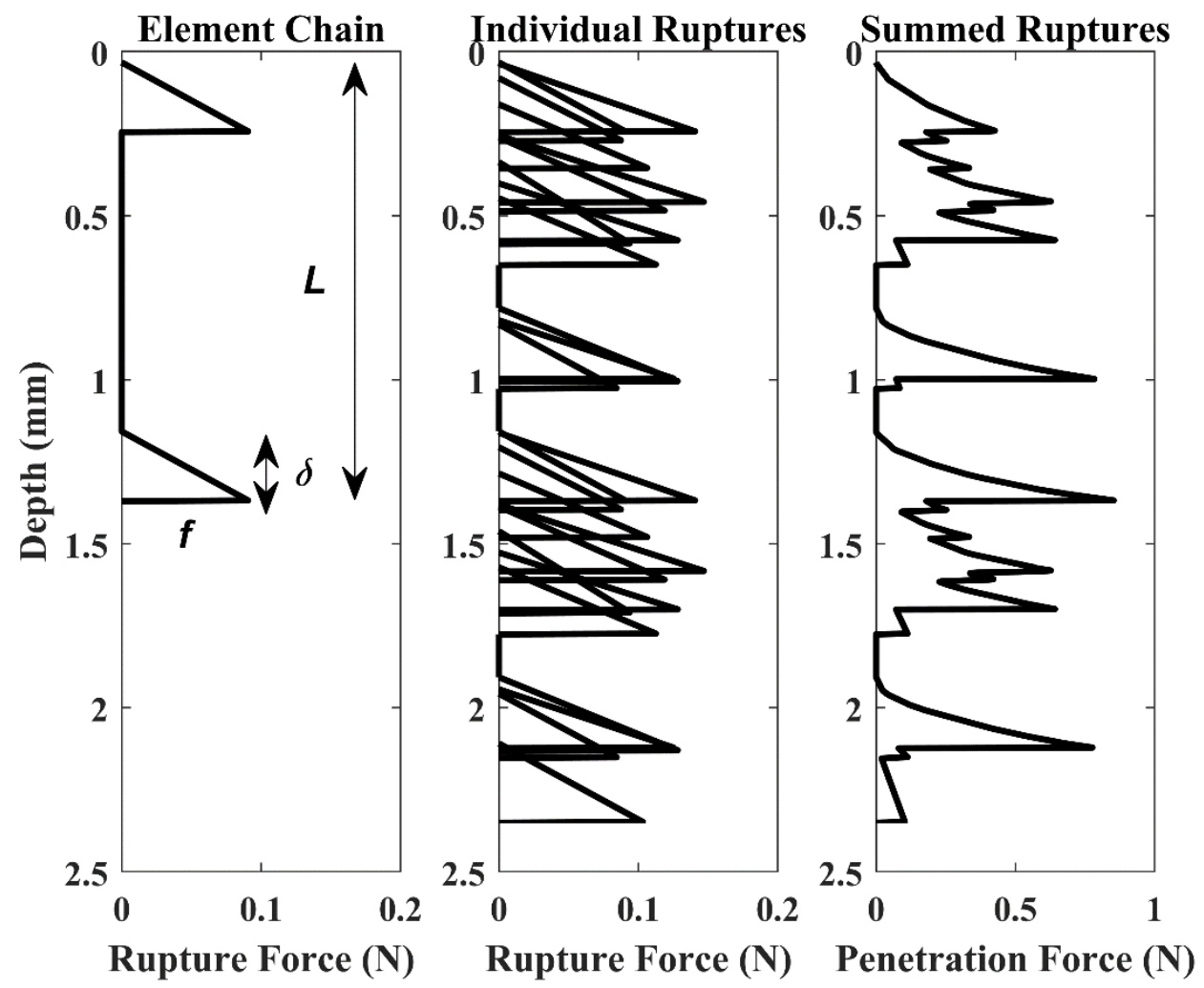

\subsubsection{Monte Carlo data inversion scheme}

Johnson and Schneebeli (1999) initially developed a Monte Carlo inversion strategy that synthesized SMP penetration-force profiles by the summation of randomly distributed elements with testable values for $L, f$, and $\delta$. Their results agreed well with measurements made in zirconia foam and indicated that the underlying theory is correct in low-density snow. Marshall and Johnson (2009) made significant improvements to the original inversion strategy by accounting for errors in the recovery of the microstructural parameters, especially when $L$ is small $(L<1 \mathrm{~mm})$, and these micromechanical and microstructural parameters were shown to be predictive of snow slope stability (Pielmeier and Marshall 2009; Lutz et al. 2009). 
Marshall and Johnson's (2009) data inversion was used to solve for the snow microstructural parameters (section 3.2.3). Figure 6 depicts the basic strategy of the Monte Carlo inversion, where individual snow elements with testable parameters $L, f$, and $\delta$, are randomly distributed. The summed contribution of the individual elements reproduces the raw penetration-force profile of the SMP when the parameters are accurately chosen, provided that the linear elastic penetration theory is sound. For clarity on the implementation and improvements made to the SMP data inversion, refer to Marshall and Johnson (2009).

\subsubsection{Microstructural parameters}

The microstructural parameters $(L, f$, and $\delta$ ) are the building blocks for additional measures of snow microstructure (section 3.2.4) and micromechanics (section 3.2.5). $L, f$, and $\delta$ are estimated via the Monte Carlo data inversion as follows:

$$
\begin{aligned}
& L=\sqrt[3]{\frac{V_{T}}{N}} \quad \begin{array}{l}
A=\pi r^{2} \text { is the area of the penetrom- } \\
\text { eter tip base and } z \text { is the depth of } \\
\text { penetration, the total volume of snow }
\end{array} \\
& \text { deformed }\left(V_{T}=A z\right) \text { causes } N \text { esti- } \\
& \text { mated ruptures. } \\
& f=\frac{\sum_{i=1}^{N} f_{i}}{N} \quad \text { The rupture force } \\
& \delta=\frac{F_{m}}{A f} L^{3}
\end{aligned}
$$

\subsubsection{Derived snow microstructural parameters}

Microstructural parameters are derived from penetration force $(F)$ and the basic microstructural parameters ( $L, f$, and $\delta$ ), the window length (calculation interval), and instrument specifications (cone diameter). Note these parameters are sensitive to the choice of the rupture threshold (section 3.2.6). These derived parameters are as follows: 


$$
\begin{aligned}
& P_{c 1}=\frac{\delta}{L} \\
& \text { The probability of contact of any mi- } \\
& \text { crostructural element, derivation } 1 \\
& P_{c 2}=\frac{N_{e}}{N_{a}} \\
& N_{e}=\frac{A \delta}{L^{3}} \\
& N_{a}=\frac{A}{L^{2}} \\
& F_{m}=\frac{F}{2} N_{e} \\
& F_{\text {med }}=\operatorname{median}(F) \\
& \rho=55.6\left(\ln \left(F_{\text {med }}\right)\right)+317.4 \quad \text { Density (Pielmeier 2003) } \\
& T_{I}=1.45+\frac{5.72 \sigma_{F}}{F_{m}} \quad \text { Textual index (Schneebeli et al. 1999) } \\
& N_{T}=\frac{A z}{L^{3}} \\
& N_{m}=\frac{N_{T}}{d z} \\
& \text { The probability of contact of any mi- } \\
& \text { crostructural element, derivation } 2 \\
& \text { The number of engaged microstruc- } \\
& \text { tural elements } \\
& \text { The number of available elements } \\
& \text { The mean penetration force normal to } \\
& \text { the penetrometer tip } \\
& \text { The median penetration force normal } \\
& \text { to the penetrometer tip } \\
& \text { The true total measured number } \\
& \text { of ruptures } \\
& \text { The mean number of measured rup- } \\
& \text { tures for a given depth window } \mathrm{dz}
\end{aligned}
$$

\subsubsection{Derived micromechanical properties}

The three fundamental microstructural parameters $(L, f$, and $\delta)$ are also used to calculate micromechanical properties of the snow that are useful for engineering purposes (Johnson and Schneebeli 1999): 


$$
\begin{array}{ll}
k=\frac{f}{\delta} & \text { The coefficient of elasticity or stiffness } \\
E=\frac{k}{L} & \text { The microscale elastic modulus } \\
\sigma=\frac{f}{L^{2}} & \text { The microscale strength }
\end{array}
$$

\subsubsection{Inversion parameters and force resolution}

The inversion process occurs within a moving window of the SMP force trace. The window size was chosen as $10 \mathrm{~mm}$, and the calculation interval was chosen as $1 \mathrm{~mm}$. We chose these parameters for fast and accurate computation with adequate depth resolution.

The minimum detectable force is understood to be the instrument noise floor. A threshold for the noise floor must be established prior to data inversion. Because of the use of the higher-range SMP force sensor, the noise floor was increased and the force resolution was decreased compared to the more common force sensor, resulting in type $\mathrm{C}_{3}$ errors. This becomes problematic for distinguishing rupture signal in soft virgin snow and vehicle belly drags.

The instrument noise floor was estimated by examining the signal above the snow surface for all SMP profiles recorded at any particular study site. The signal range was calculated within a moving window throughout eight realizations for windows of increasing size (from 1 sample to 250 samples). Figure 7 displays the boxplots of these events as a summary statistic.

Figure 7. The boxplots of the instrument noise floor for increasing window lengths.

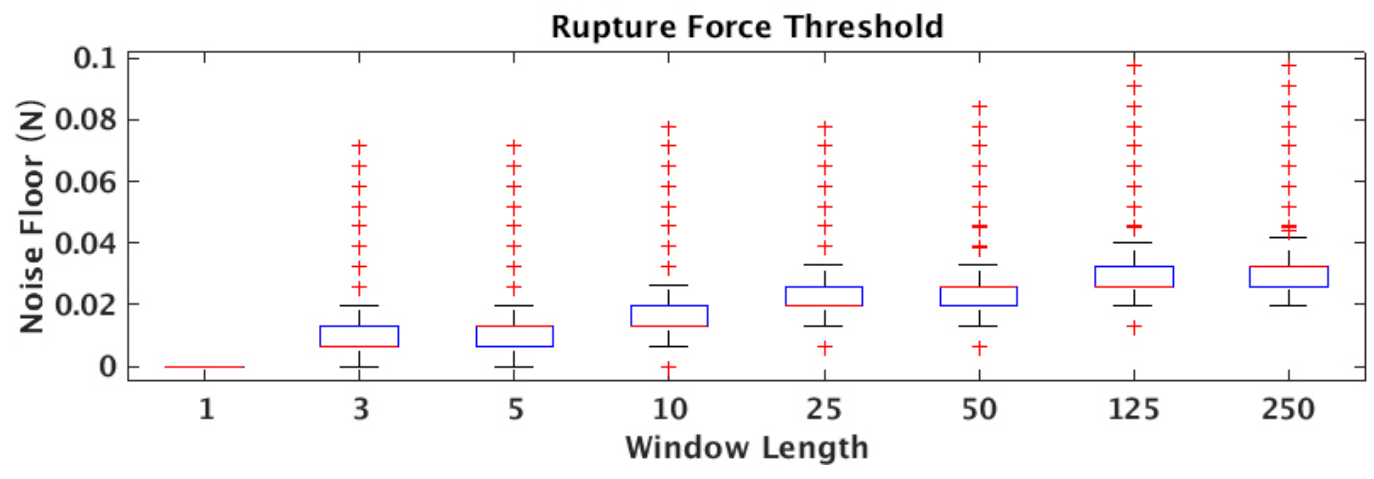


The microphysical properties were inverted for using the median threshold value for each window size. The force sampling discretization of the SMP used in this study is $0.0065 \mathrm{~N}$. This allows for a few possible threshold selections $(0,0.0065,0.013,0.0195,0.026$, or $0.0325 \mathrm{~N})$. The coarse force discretization is problematic for soft snow where the rupture force becomes enveloped by the noise floor, as this creates type $\mathrm{C}_{3}$ error. Figure 8 depicts the drift-corrected SMP trace from the virgin snow at the various force thresholds. Type $\mathrm{C}_{3}$ errors are observed in data segments shown in red.

Figure 8. The drift-corrected SMP trace, as in Figs. 3 and 5, tested at force thresholds that distinguished null-rupture events. Data segments that did not experience any detectable ruptures of snow elements are shown in red. We recommend the $0.0195 \mathrm{~N}$ threshold because the air signal is correctly identified and C3 error type is minimized.
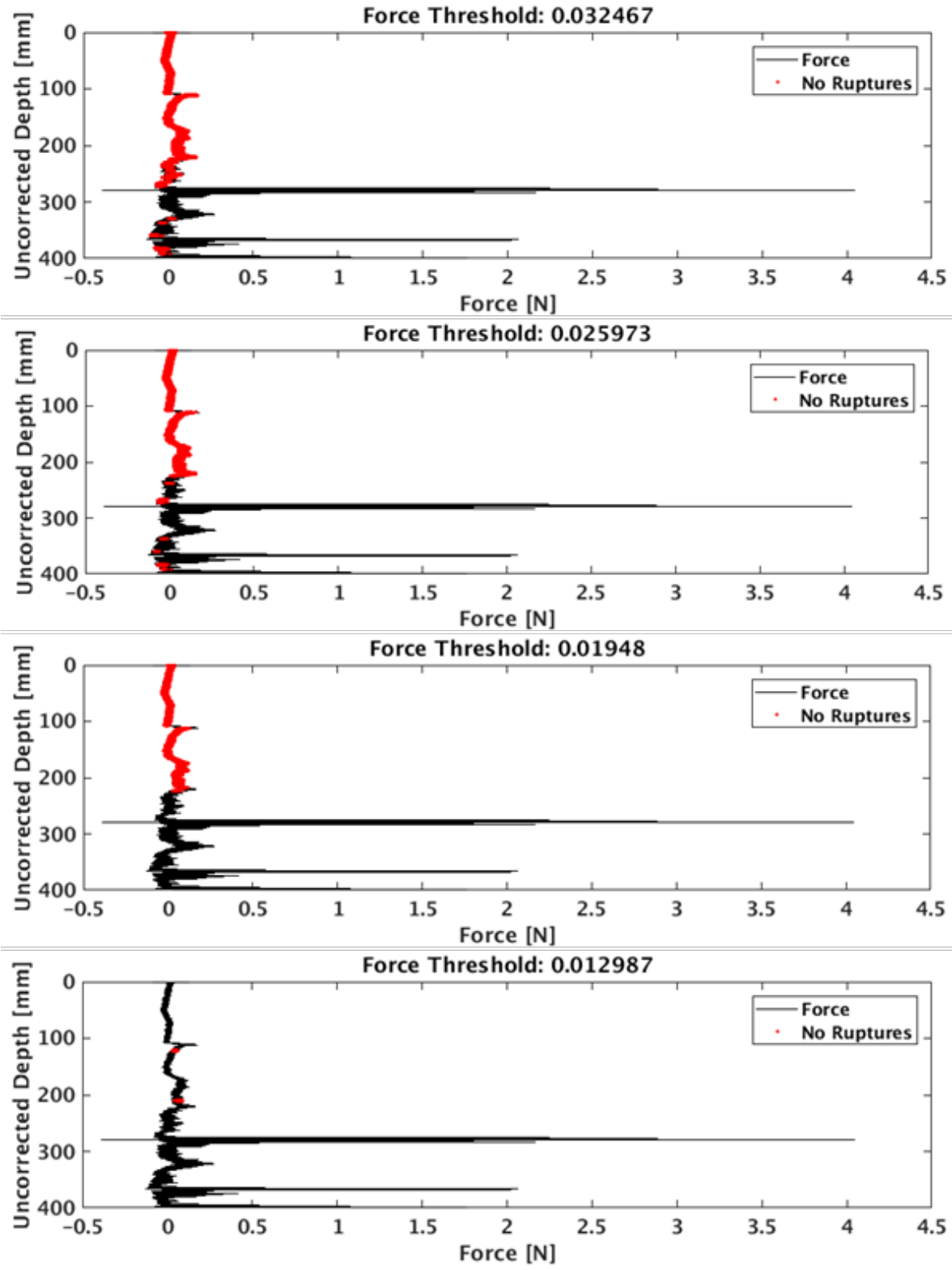
The $0.013 \mathrm{~N}$ threshold is the lowest value that detected the absence of element rupture, albeit false identification within the snowpack. The $0.0195 \mathrm{~N}$ threshold correctly distinguishes the noise floor in the air gap and the snow signal at greater rupture forces. The greater thresholds correctly distinguish the two melt-refreeze crusts within the virgin snow. This serves as a check on the lower error bound of this method for a vehicle mobility study that has large penetration-force requirements. From the results of Figure 8, we selected the $0.0195 \mathrm{~N}$ threshold for the data inversion. The $0.0195 \mathrm{~N}$ threshold exceeds the previously accepted value of $0.014 \mathrm{~N}$ by nearly an entire force discretization. Given the current development of SMP hardware, we must accept the inability to resolve element ruptures within very soft snow. Future work will aim to design a high-resolution penetrometer with a larger dynamic range to allow accurate characterization of both very soft virgin snow and very hard vehicle-compacted snow or groomed snow surfaces.

\subsection{Instrument observation correlation analysis}

\subsubsection{Theory of linear correlation}

The linear correlation coefficient was applied to the NATC data to draw meaningful relationships between the SMP microphysical parameters and the macroscale snow instruments. The linear correlation coefficient seeks to justify the existence of a physical relationship between two variables by testing whether the variations in the observed values of variable $x_{i}$ are correlated with the variations in the observed values of variable $x_{j}$ (Bevington and Robinson 2003). Statistical correlation does not alone prove a physical relationship, but it is a powerful data-exploration step. Equation (2) calculates the linear correlation coefficient from an experimental data set:

$$
r_{i j}=\frac{s_{i j}^{2}}{s_{i} s_{j}}
$$

where

$r_{i j}=$ the linear correlation coefficient between any two variables $x_{i}, x_{j}$;

$s_{i j}^{2}=$ the covariance between observations of variables $x_{i}, x_{j}$;

$s_{i}=$ the standard deviation of observations of variable $x_{i}$; and

$s_{j}=$ the standard deviation of observations of variable $x_{j}$. 
Values of $r$ range from 0 to \pm 1 with $o$ indicating no correlation and 1 indicating perfect correlation. However, the correlation coefficient does not solely indicate the goodness of correlation. Here, $r$ is compared to the probability distribution for the parent population, which is completely uncorrelated (Bevington and Robinson 2003). Equation (3) is the probability that a random sample of $N$ data points drawn from the uncorrelated parent distribution would yield an experimental linear correlation coefficient greater than or equal to the observed magnitude of $r$ (Bevington and Robinson 2003).

$$
P_{c}(r ; N)=2 \int_{|r|}^{1} p_{r}(r ; v) d r
$$

where

$$
p_{r}(r ; v)=\frac{1}{\sqrt{\pi}} \frac{\Gamma[(v+1) / 2]}{\Gamma(v / 2)}\left(1-r^{2}\right)^{(v-2) / 2},
$$

is the probability that any random sample of uncorrelated experimental data points would yield an experimental linear correlation coefficient equal to $r_{i j}$ and where

$$
\begin{aligned}
r= & \text { the calculated linear correlation coefficient, } \\
v= & N-2 \text { the number of degrees of freedom for an experimental } \\
& \text { sample of } N \text { data points, and } \\
\Gamma= & \text { the Gamma function. }
\end{aligned}
$$

Correlations are deemed significant if the probability value derived from equation (3) is less than or equal to the desired level of statistical significance. $P_{c} \leq 0.05$ determined test significance for the ram hardness study; however, $P_{c} \leq 0.1$ determined test significance for the shear vane and LWD correlations. The larger rejection region was used for the shear vane and LWD studies because fewer sampled data are available for the analysis of these instruments.

\subsubsection{Application of linear correlation}

Each of the 16 microphysical parameters of the SMP data inversion and the additional raw penetration force enabled 17 independent variables to be correlated with the ram hardness measurements, shear-stress measurements from the shear vane, and elastic modulus estimates from the LWD. The data are reduced to the median statistic for each measurement at a 
test location. The instruments were compared on equivalent measurement depths as follows. The ram median hardness value for the entire snow penetration was correlated with the equivalent penetration depths for median values of the SMP microphysical parameters. The shear vane was inserted $50 \mathrm{~mm}$ into the snowpack, and only the upper $50 \mathrm{~mm}$ of the SMP profile, corresponding to the same $50 \mathrm{~mm}$ depth interval, were considered in the correlation. The median values for the entire SMP profile through approximately $10 \mathrm{~cm}$ of the groomed snow-road surfaces were used for correlation with the LWD, as this was the estimated snow depth that controlled the deformation caused during the LWD test.

For this analysis, the dynamic range of the measured data is important. Sample sizes used in the correlation analysis depend on the number of test locations where the experiment was conducted and the range of snow conditions observed. The ram gives the most prevalent data set $(N=24)$ as this instrument could perform in all three snow conditions, providing one median data point for each, and was tested at eight locations. The shear vane was limited to hardened snow that could support shear load $(N=11)$. These data are composed of vehicle ruts of nine test points and vehicle belly drags from two test points. The LWD experiment is the most limited in population size $(N=5)$, as this experiment could be conducted only on processed snow roads where the SMP had difficulty penetrating. Section 4.3 provides additional information regarding snow conditions and testpoint usefulness for the LWD at NATC. 


\section{Results and Discussion}

\subsection{Rammsonde}

Ram and SMP profiles were gathered from the colocated test points and were classified into three snow conditions: virgin snow, vehicle belly drag, and tire ruts. Correlation analysis was conducted using the median values from each snow type at a particular location. Abele (1963) correlated ram hardness with unconfined compressive strength. Because ram hardness measured at NATC was typically too low, Abele's (1963) correlation does not yield physically meaningful results for this study. Of the 17 possible correlations, 4 are statistically significant: rupture force $(f)$, mean penetration force $\left(F_{m}\right)$, density $(\rho)$, and strength $(\sigma)(p \leq 0.05)$. Figure 9 summarizes the data that provide significant correlation results. Figure 10 provides the scatter plots resulting in significant correlations, and Figure 11 provides the overview of all correlations.

The NATC data express the trend that rupture force, penetration force, density, strength, and ram hardness increase when the snow was deformed by the vehicles. However, judging this trend using the notched boxplots, it is not statistically significant, as the notches overlap in many cases (Figure 9). This indicates that the range of parameters, rather than the median values, may be more predictive of the snow type (virgin snow, belly, or rut). The confidence interval of these relationships is quantified using correlation analysis.

\subsection{Shear vane}

The shear-vane study was limited to only 11 sites, significantly reducing the power of the correlation analysis. Additionally, the shear-vane response is variable and spans the entire range of recordable shear strengths (from a minimum of $o$ to the maximum of $130 \mathrm{kPa}$ ). The data summary in the boxplot of Figure 12 indicates that sites of similar snow condition have uncorrelated instrument response. The smaller sample population will inherently reduce the confidence value of the result, so we chose a significance level of $p \leq 0.1$ for this analysis. Of the 17 microphysical parameters, 3 had statistically significant correlations: $N_{T}, N_{a}$, and $N_{m}$ (Figure 12). The inverse relationship shows that a snowpack stronger in shear will experience fewer ruptures when it fails under an applied stress. Figure 13 provides the overview of all tested correlations. 
Figure 9. The boxplot summary of SMP and ram data that yield significant correlation $(p \leq 0.05)$. The red crosses are outliers.

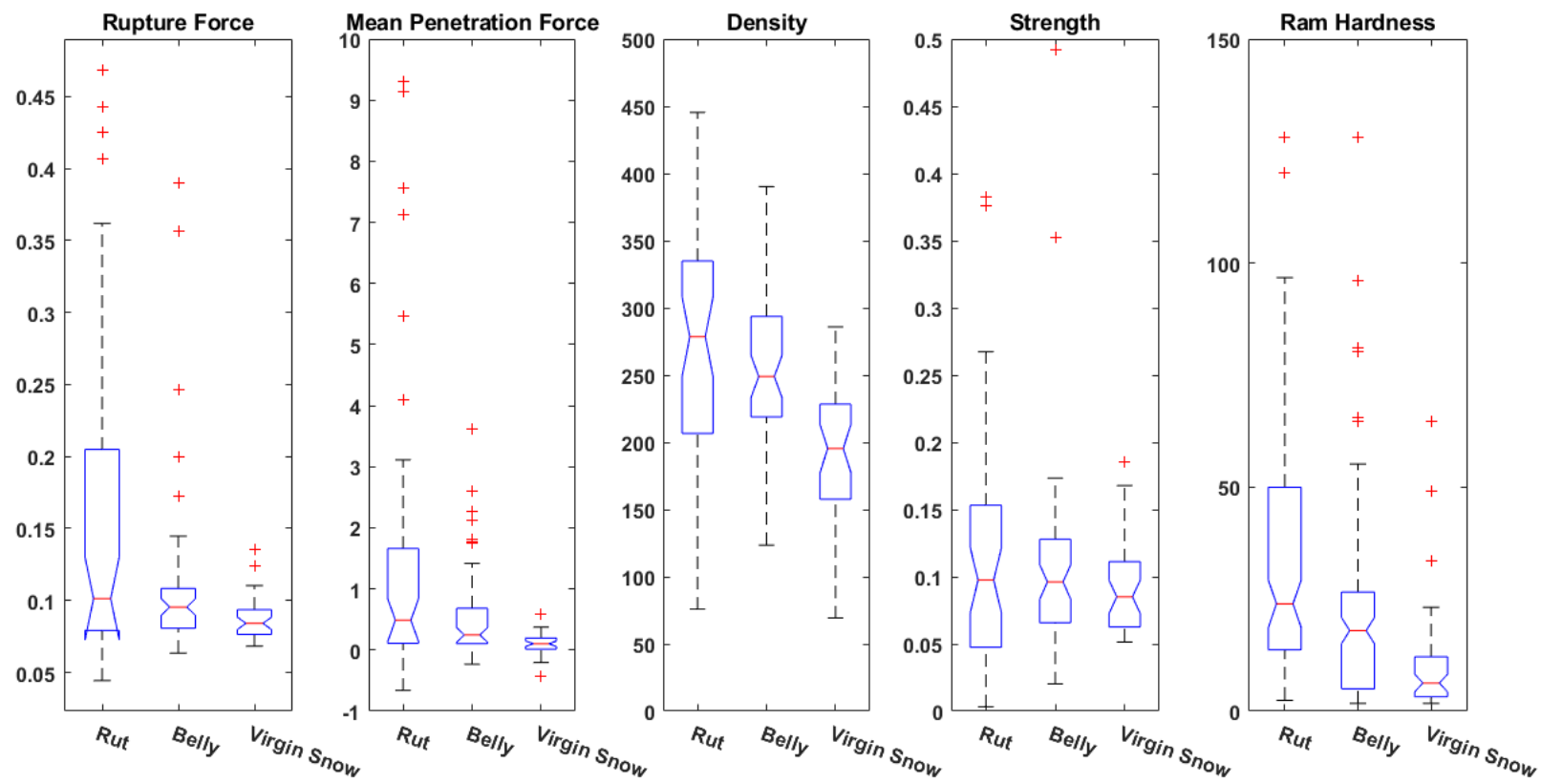

Figure 10. Statistically significant correlations between SMP microphysical parameters and the ram. The marker style identifies the site location, and the color represents the snow type.
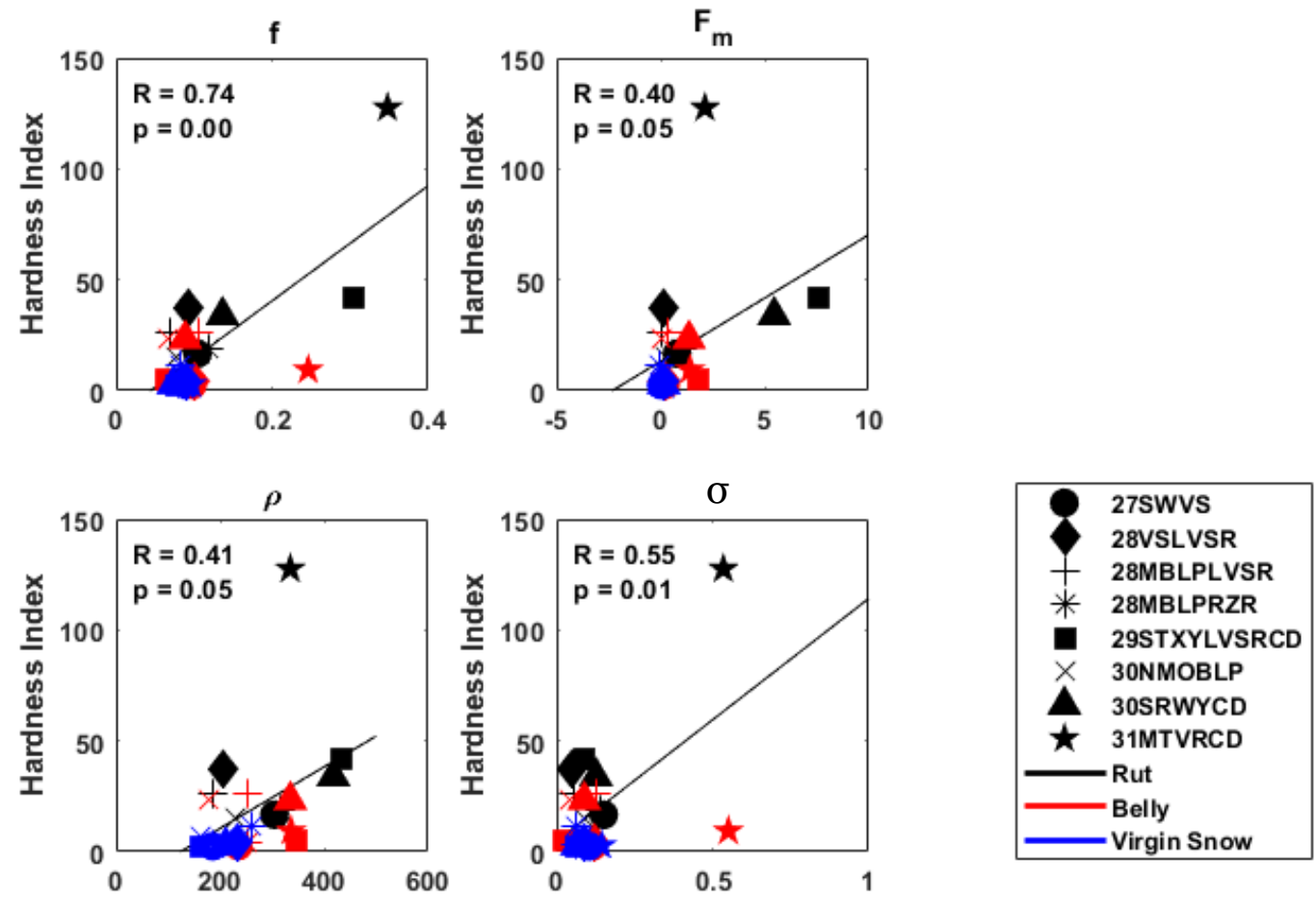
Figure 11. Results of the correlation between the ram hardness index and the SMP microphysical parameters.
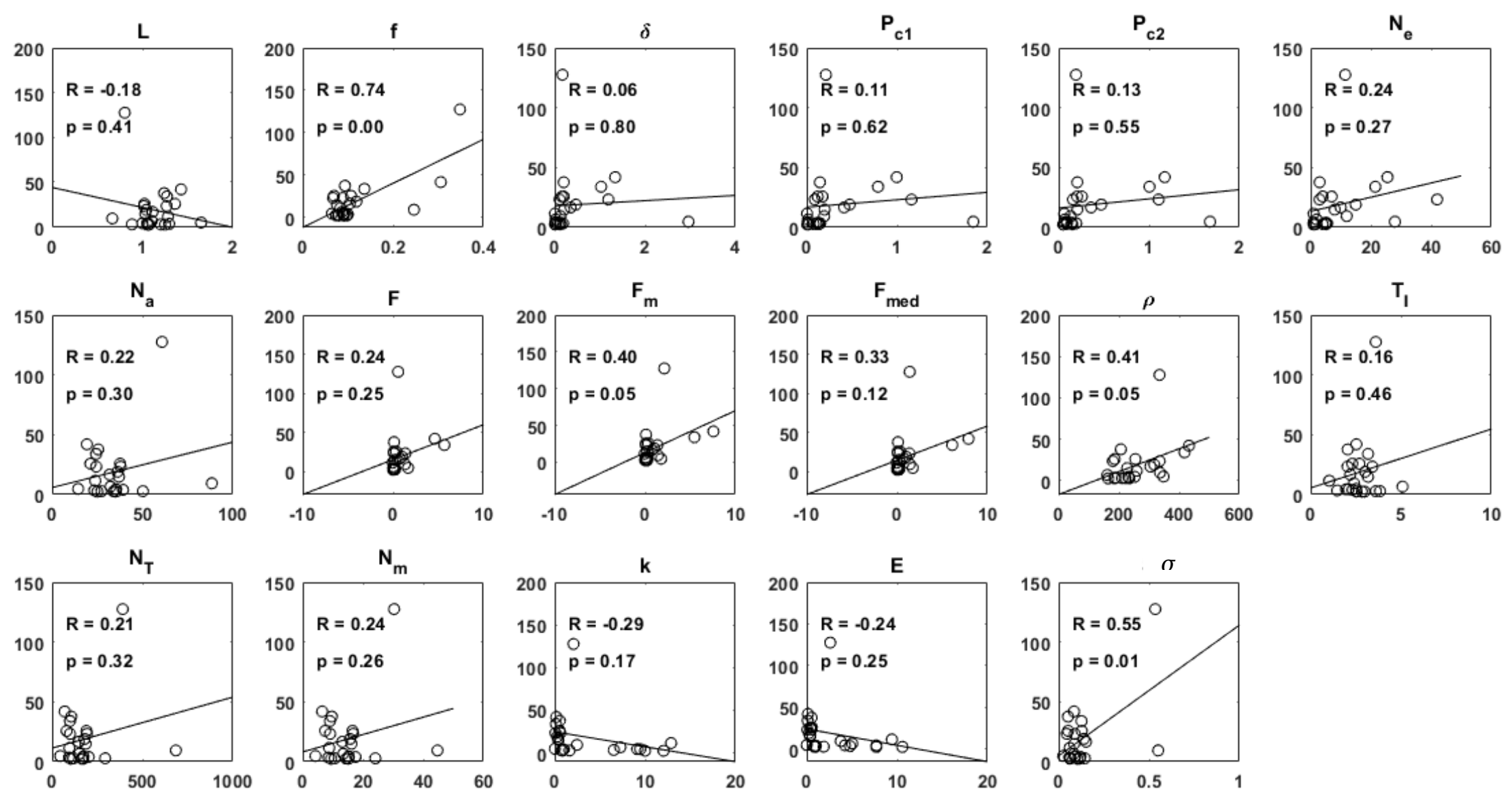
Figure 12. Statistically significant correlations between SMP microphysical parameters and the shear-vane measurements $(p \leq 0.1)$. The boxplot summarizes the shear-vane measurements from 11 test locations.
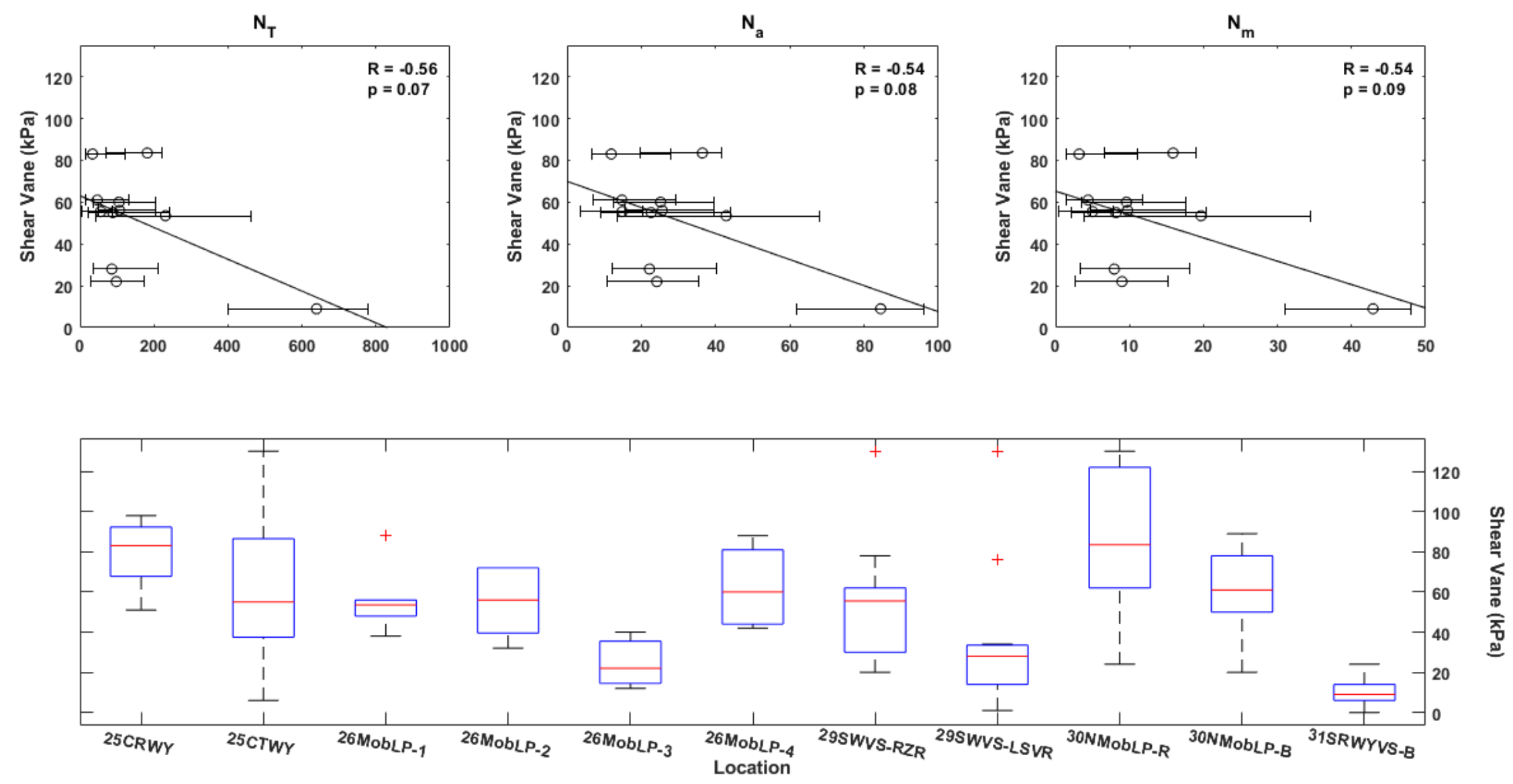
Figure 13. Results of the correlation between shear-vane stress and the SMP microphysical parameters.
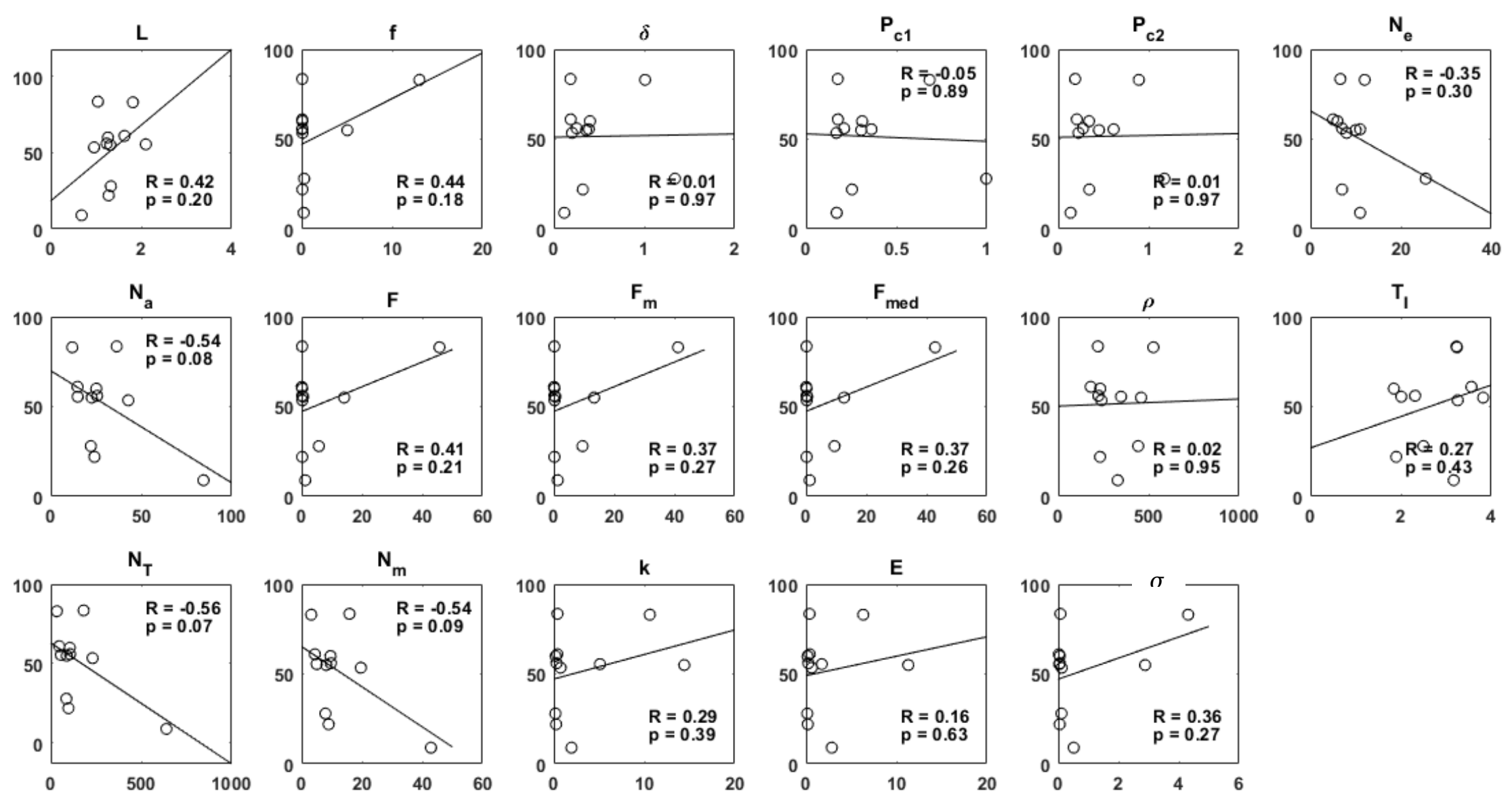


\subsection{Light Weight Deflectometer}

The LWD was collocated with SMP measurements on the groomed runway and taxiway at NATC. These tests occupied 10 locations on the fresh snow road surfaces and within vehicle ruts (notated in Figures 14 and 15 by RR and LR for right rut and left rut, respectively). Correlation analysis was applied to determine if the snow at these locations behaves in a linear elastic manner. The effective elastic modulus $\left(E^{*}\right)$ is derived from the linear slope of the deflection measured at the central geophone and the stress applied to the snow column. To create a distribution of effective elastic modulus, the bootstrapping method was applied to the least-squares regression (Efron and Tibshirani 1986). Two samples were removed at random from the correlation analysis, and the linear slope was refit. This procedure was replicated 250 times for each site location. Figure 14 displays the results of the correlation analysis. The median value of the $E^{*}$ distribution was chosen to represent the site condition. Locations that have a negative slope or $p \leq 0.05$ were removed from the analysis.

The correlation analysis was repeated between the LWD $E^{*}$ and the SMP microphysical parameters. No significant correlation was found between these measurements. Figure 15 presents the findings of the correlation analysis. This indicates that there is a scaling between the microscale mechanical properties that the SMP measures and the macroscale properties measured by the LWD, which is not well understood. Marshall and Johnson (2009) and Marshall (2005) attempted to develop a micro-to-macro scaling law but with low-density soft snow. Both a new theory for inverting SMP signals for micromechanical properties, which relaxes the assumption of low-density snow, and a scaling law appropriate to this type of hard snow are required to relate the SMP observations at the microscale and the macroscale properties measured by the LWD. 
Figure 14. Results for the effective linear elastic property of groomed snow roads at NATC. Locations with negative slope or p-value $>0.05$ were excluded from the correlation analysis.
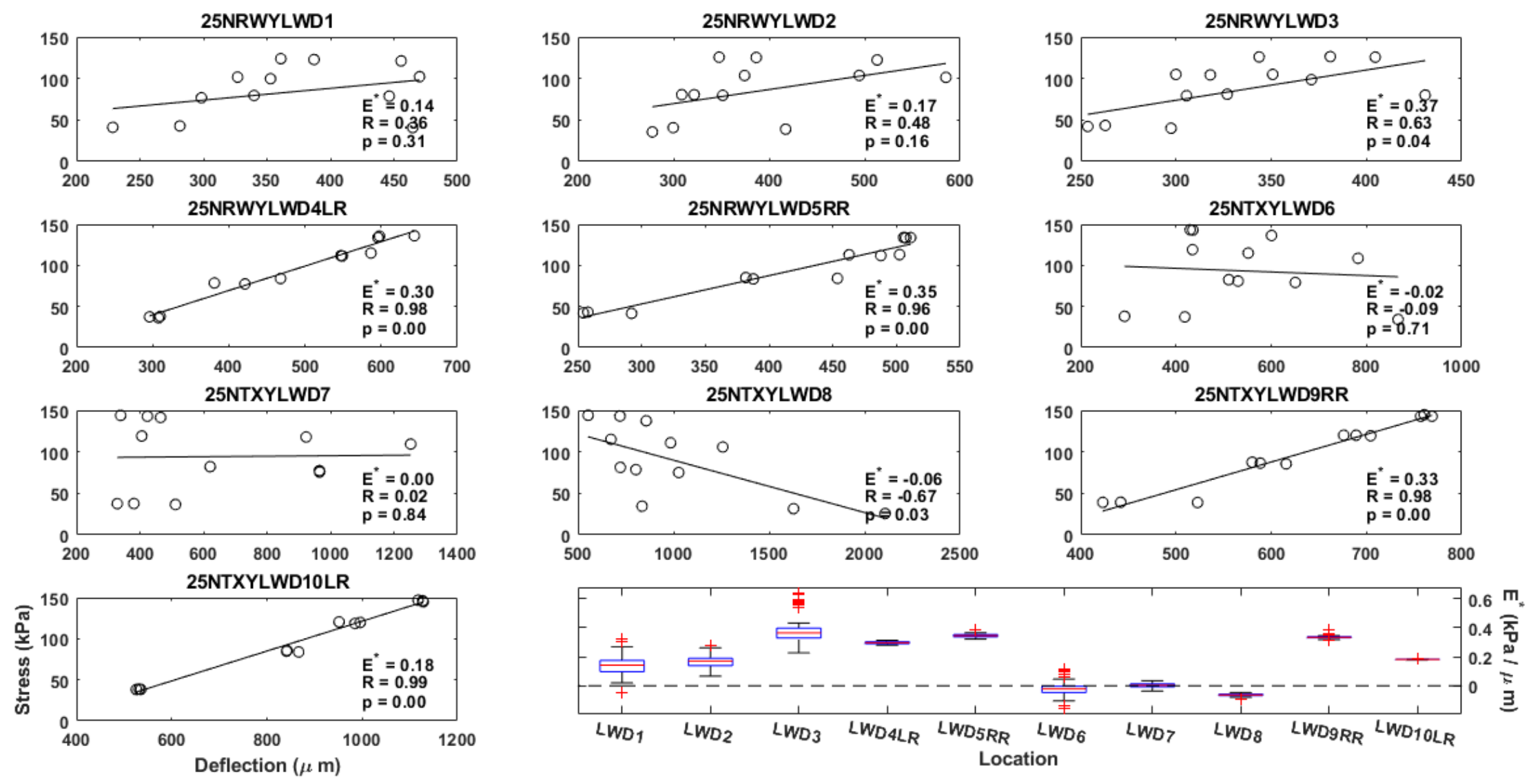
Figure 15. Results of the correlation analysis between $E^{*}$ and the SMP microphysical parameters. No significant correlation was found.
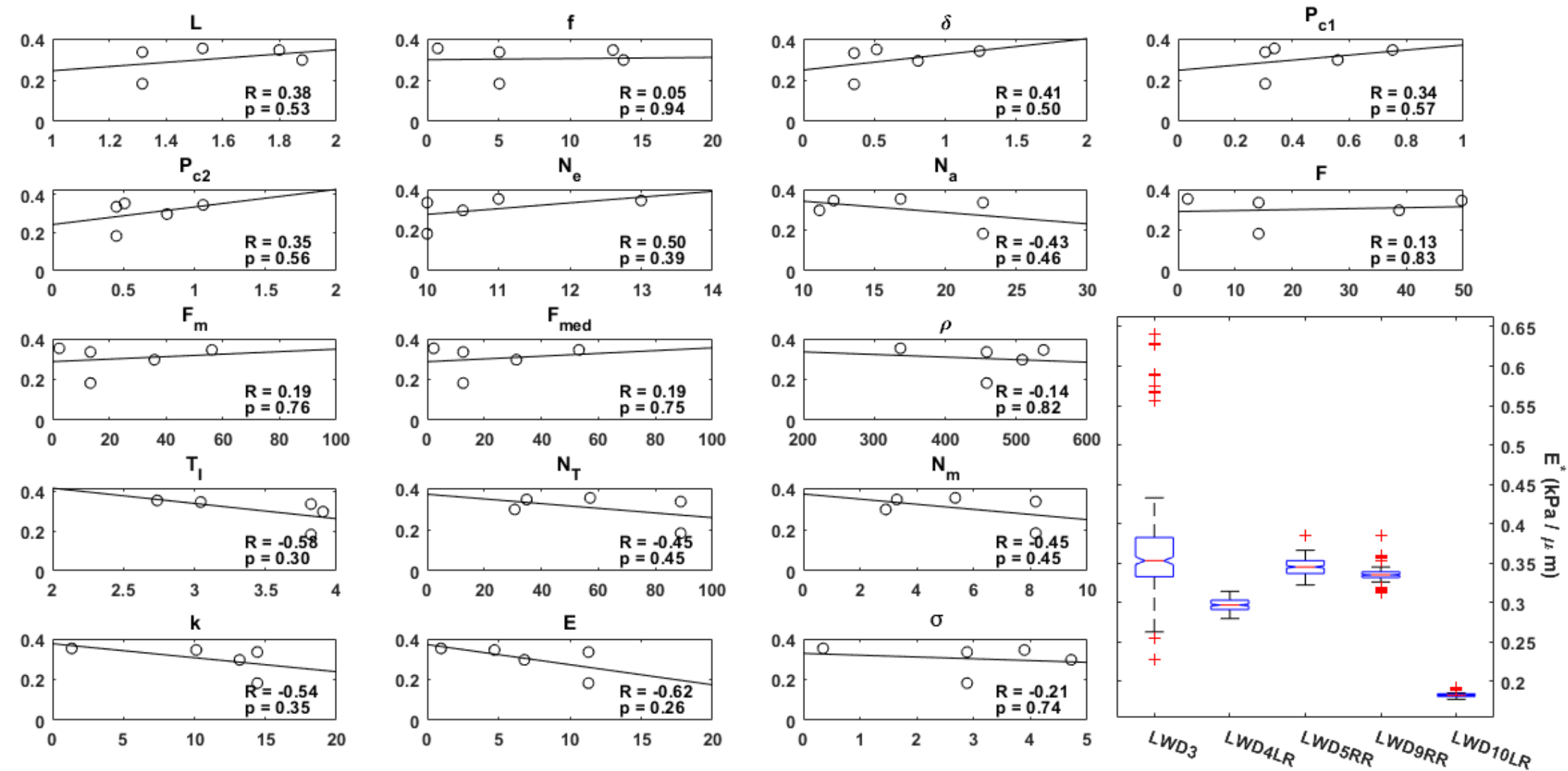


\section{Conclusions}

The 2018 winter testing at NATC allowed evaluation of the SMP for more compacted snow and comparison of the SMP with more traditional snow characterization instruments, specifically the ram penetrometer, shear vane, and the LWD. The methods and results presented within this report are preliminary. We developed an automated signal-processing routine for the SMP signal by joining the preprocessing and classification strategy of Lutz (2009) with the inversion methods of Marshall and Johnson (2009). Measured ruptures are sensitive to the force discretization during signal analog-to-digital conversion and during the inversion process. We find it is more robust to study rupture force than penetration force because the magnitude of the rupture is not dependent on the absolute penetration force, so this parameter does not suffer from errors caused by instrument drifting. Type $\mathrm{C}_{3}$ errors cannot be remedied by signal processing and must be accepted as a limitation of the hardware; future efforts will focus on penetrometer development with a larger dynamic range and higher force resolution. Other methods of analysis were trialed, including using the maximum value and normalizing each site by the median prior to correlation analysis. However, the median value correlation provided the strongest results. The significant correlation between ram hardness and SMP strength coincides with Abele's (1963) findings, though the strength reported by the SMP is a multimode strength rather than unconfined compressive strength. This serves as a check on the methods being developed in a lower range of snow strengths and densities (approximately 100$\left.450 \mathrm{~kg} / \mathrm{m}^{3}\right)$.

Shear-vane measurements were restricted to locations with compacted snow, primarily vehicle ruts, with two exceptions of measurements made in vehicle belly drags on 30 January at the North mobility loop entrance and 31 January at the South runway. The snow was strong enough to support these measurements because the mobility loop snow was compacted by many vehicle passes-becoming strongly sintered-and a daytime warming period late in the week was met with very cold overnight temperatures, creating a melt-freeze cycle that formed strongly bonded snow. The small range of testable snow conditions for the shear vane limited the study and likely resulted in weakened correlations. Several centimeters of fresh snow fell during the study, leaving a soft surface layer atop the 
groomed surface. For the LWD experiment, the vehicle compaction (rutting) provided the additional stiffening to the snow road necessary for linear elastic behavior because repeated LWD impacts in soft snow nonlinearly decrease the deflection of the central geophone. Insignificant correlation results likely arise from the small sample size $(N=5)$ and the similar snow conditions at the LWD test locations.

The SMP has not previously been applied to vehicle-driven snow. Processed snow roads and snow after deformation by vehicles exhibit high density and strengths that exceed the capability of the current SMP design. By using a $500 \mathrm{~N}$ force sensor in the SMP, a larger dynamic range of snow conditions was measured at the expense of lower force resolution. Even with this higher range sensor, there were many snow conditions relevant to this study that were too hard for the SMP. To further improve the capability of the SMP for vehicle studies, a more powerful tool that can drive through very hard snow at a constant rate, minimizes type $\mathrm{C}_{2}$ errors, and uses a larger bit analog-to-digital converter to remediate type $\mathrm{C}_{3}$ errors should be developed to better resolve penetration forces in hard snow. Anchoring to a vehicle, similar to the LWD, is likely required. Advancements to the instrumentation should also be met with advancements to the penetration theory. Accounting for snow ruptures influenced by interlocking snow elements away from the penetrometer tip can improve the application of the SMP. Accurate and large spatial scale measurement of the snow microphysics can serve as initial and boundary conditions for snow models and be a map for the analysis of remote-sensing imagery for vehicle mobility. 


\section{References}

Abele, G. 1963. A Correlation of Unconfined Compressive Strength and Ram Hardness of Processed Snow. Technical Report 85. Hanover, NH: U.S. Army Cold Regions Research and Engineering Laboratory. http://hdl.handle.net/11681/5579.

Anderson, D. L., and C. S. Benson. 1963. "The Densification and Diagensis of Snow.” In Ice and Snow: Properties, Processes, and Applications, ed. W. D. Kingery, 391411. Cambridge, MA: M.I.T. Press.

ASTM International. 2018. Standard Test Method for Field Vane Shear Test in Saturated Fine-Grained Soils. ASTM D2573/D2573M-18. West Conshohocken, PA, 2018: ASTM International. https://doi.org/10.1520/D2573_D2573M-18.

Bader, H. 1954. Snow and Its Metamorphism. Wilmette, IL: U.S. Army Snow, Ice and Permafrost Research Establishment.

Bevington, P. R., and D. K. Robinson. 2003. Data Reduction and Error Analysis for the Physical Sciences. 3rd ed. New York: McGraw Hill.

Efron, B., and R. Tibshirani. 1986. "Bootstrap Methods for Standard Errors, Confidence Intervals, and Other Measures of Statistical Accuracy.” Statistical Science 1 (1): 77-77. doi: 10.1214/ss/1177013817.

Johnson, J. B., and M. Schneebeli. 1999. "Characterizing the Microstructural and Micromechanical Properties of Snow." Cold Regions Science and Technology 30 (1-3): 91-100. doi: 10.1016/So165-232X(99)ooo13-0.

Lutz, E. R. 2009. "Spatial and Temporal Analysis of Snowpack Strength and Stability and Environmental Determinants on an Inclined, Forest Opening." PhD diss., Montana State University.

Marshall, H.-P. 2005. "Snowpack Spatial Variability: Towards Understanding Its Effect on Remote Sensing Measurements and Snow Slope Stability." PhD thesis, University of Colorado.

Marshall, H.-P., and Johnson, J. B. 2009. "Accurate Inversion of High-Resolution Snow Penetrometer Signals for Microstructural and Micromechanical Properties." Journal of Geophysical Research 114 (F4): Fo4016. doi: 10.1029/2009JFo01269.

Pielmeier, C. 2003. “Textural and Mechanical Variability of Mountain Snowpacks.” PhD thesis, University of Berne.

Pielmeier, C., and H.-P. Marshall. 2009. "Rutschblock-Scale Snowpack Stability Derived from Multiple Quality-Controlled SnowMicroPen Measurements.” Cold Regions Science and Technology 59 (2-3): 178-184. http://dx.doi.org/10.1016/j.coldregions .2009 .06 .005 .

Pielmeier, C., and M. Schneebeli. 2003. "Stratigraphy and Changes in Hardness of Snow Measured by Hand, Ramsonde and Snow Micro Penetrometer: A Comparison with Planar Sections." Cold Regions Science and Technology 37 (3): 393-405. doi: 10.1016/So165-232X(03)00079-X. 
Schneebeli, M., and J. B. Johnson. 1998. "A Constant-Speed Penetrometer for HighResolution Snow Stratigraphy.” Annals of Glaciology 26:” 107-111. doi: 10.1017/So260305500014658.

Schneebeli, M., C. Pielmeier, and J. B. Johnson. 1999. "Measuring Snow Microstructure and Hardness Using a High Resolution Penetrometer." Cold Regions Science and Technology 30 (1-3): 101-114. https://doi.org/10.1016/S0165-232X(99)00030-0.

Shapiro, L. H., J. B. Johnson, M. Sturm, and G. L. Blaisdell. 1997. Snow Mechanics: Review of the State of Knowledge and Applications. CRREL Report 97-3. Hanover, NH: U.S. Army Cold Regions Research and Engineering Laboartory. http://hdl.handle.net/11681/9238.

Shoop, S. A., M. A. Knuth, and W. L. Wieder. 2014. Vehicle Impact Testing of Snow Roads at McMurdo Station, Antarctica. ERDC/CRREL TR-14-9. Hanover, NH: U.S. Army Engineer Research and Development Center. http://hdl.handle.net/11681 $\angle 5482$.

Shoop, S. A., J. Uberuaga, W. L. Wieder, and T. D. Melendy. 2016. Snow-Road Construction and Maintenance. ERDC/CRREL TR-16-16. Hanover, NH: U.S. Army Engineer Research and Development Center. http://hdl.handle.net/11681 $\angle 20651$.

Wieder, W. L., S. A. Shoop, and L. A. Barna. 2019. Using the Light Weight Deflectometer to Assess Groomed Snow and Ice Surfaces. ERDC/CRREL TR-19-5. Hanover, NH: U.S. Army Engineer Research and Development Center. https://hdl.handle.net /11681/32732. 


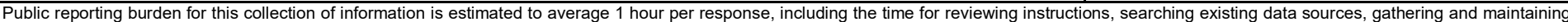

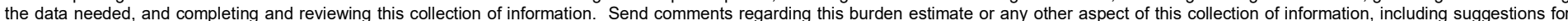

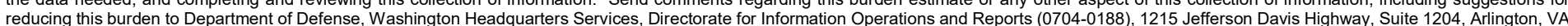

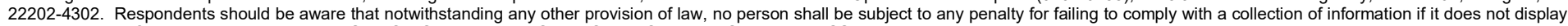
a currently valid OMB control number. PLEASE DO NOT RETURN YOUR FORM TO THE ABOVE ADDRESS.
1. REPORT DATE (DD-MM-YYYY)
2. REPORT TYPE
August 2019
Technical Report/Final

\section{TITLE AND SUBTITLE}

SnowMicroPenetrometer Applications for Winter Vehicle Mobility

3. DATES COVERED (From - To)

\section{5a. CONTRACT NUMBER}

5b. GRANT NUMBER

5c. PROGRAM ELEMENT NUMBER

\section{AUTHOR(S)}

Tate G. Meehan, Hans-Peter Marshall, Elias J. Deeb, and Sally A. Shoop

5d. PROJECT NUMBER

465395 \& 471941

5e. TASK NUMBER

5f. WORK UNIT NUMBER

\section{PERFORMING ORGANIZATION NAME(S) AND ADDRESS(ES)}

8. PERFORMING ORGANIZATION REPORT NUMBER

U.S. Army Engineer Research and Development Center (ERDC)

Cold Regions Research and Engineering Laboratory (CRREL)

ERDC/CRREL TR-19-14

72 Lyme Road

Hanover, NH 03755-1290

\section{SPONSORING / MONITORING AGENCY NAME(S) AND ADDRESS(ES)}

Assistant Secretary of the Army for Acquisition, Logistics, and Technology

103 Army Pentagon

Washington, DC 20314-1000

10. SPONSOR/MONITOR'S ACRONYM(S)

ASA(ALT)

11. SPONSOR/MONITOR'S REPORT NUMBER(S)

\section{DISTRIBUTION / AVAILABILITY STATEMENT}

Approved for public release; distribution is unlimited.

\section{SUPPLEMENTARY NOTES}

ERDC 6.2 Boreal Aspects of Ensured Maneuver (BAEM)

\section{ABSTRACT}

The U.S. Army Cold Regions Research and Engineering Laboratory provides technical support to military forces, one area being vehicle mobility modeling over snow. Many factors control vehicle performance, including the vehicle specifications and the land surface conditions. However, estimating snow macromechanical properties - such as elastic modulus, stiffness, and strength - is critical for understanding how effectively a vehicle will travel over snow-covered terrain. Vehicle instrumentation data and observations of the snow pack are necessary to improve the estimates of winter vehicle performance. Currently, snow depth and bulk snow density alone drive the available mobility performance index.

This research deployed a SnowMicroPenetrometer (SMP) to measure hard, vehicle-compacted snow and groomed snow roads. Microstructural and micromechanical properties derived from the SMP data analysis were correlated to the Rammsonde penetrometer hardness, an established snow instrument, and to the shear-strength test vane and Light Weight Deflectometer, which are common in soil and aggregate layer assurance methods in road construction. Correlating these tools requires a new theory for inverting SMP signals for micromechanical properties that relaxes the assumption of low-density snow. Additionally, a scaling law appropriate to this type of hard snow is required to relate the SMP observations of the microscale and the macroscale properties.

\section{SUBJECT TERMS}

Bearing capacity; Macrophysics; Microphyics; Mobility; Penetrometers; Snow mechanics; SnowMicroPenetrometer; Snow--Testing; Trafficability; Vehicles, Military

\section{SECURITY CLASSIFICATION OF:}

\section{a. REPORT}

Unclassified

\section{b. ABSTRACT}

Unclassified

\section{c. THIS PAGE}

Unclassified
17. LIMITATION OF ABSTRACT

SAR
18. NUMBER OF PAGES

42 19a. NAME OF RESPONSIBLE PERSON

19b. TELEPHONE NUMBER (include area code) 